\title{
Dynamic characteristics of coupling model of valve-controlled cylinder parallel accumulator
}

\author{
Zhiqiang $\mathrm{Xu}^{1}$, Wanli $\mathrm{Li}^{1}{ }^{1,}$, Xiangyong $\mathrm{Liu}^{1}$, and Zhixin $\mathrm{Chen}^{2}$ \\ ${ }^{1}$ School of Mechanical Engineering, Tongji University, Shanghai 201804, PR China \\ ${ }^{2}$ Fishery Machinery and Instrument Research Institute, Chinese Academy of Fishery Science, Shanghai 200092, PR China
}

Received: 8 October 2018 / Accepted: 24 January 2019

\begin{abstract}
To solve the electro-hydraulic control problems caused by the accumulator's passive involvement, the internal principle of the valve-controlled luffing cylinder was explored based on one ship crane; comparison models with and without the accumulator were established, and experiments were performed to verify the dynamic characteristics. By comparing simulations with experimental data, it was found that in the outstretch stage of the cylinder, the accumulator releases energy, accelerates the extension of the cylinder, and increases the response velocity. However, the accumulator also reduced the precision of location control. Therefore, to effectively solve the problem of fluctuation rate in the outstretch stage, experiments were conducted to adjust the valve-core opening according to the energy-release characteristics of the accumulator. In the retracting stage of the cylinder, the accumulator absorbed oil and inhibited the pressure fluctuation of the cylinder effectively. Finally, the feasibility of the compensation solution was verified through the experiments.
\end{abstract}

Keywords: Accumulator / dynamic model / compensation control / experiment verification

\section{Introduction}

In the ship crane, the valve-controlled luffing cylinder can be used for wave compensation to keep the hoist stable. However, the active compensation control method often has problems such as large power consumption and sudden hit. The accumulator is an important hydraulic element, and it is widely applied when designing energy-saving and anti-damping systems [1-3]. Thus, the accumulator is applied in the valve-controlled luffing cylinder to reduce the power consumption. In order to get a precise position track, especially in harsh sea conditions, electro-hydraulic proportion control requires that the hydraulic system should have a timely velocity-controlled feature. Due to the energy's passive involvement in the accumulator, the accumulator causes some difficulties to electro-hydraulic proportion control, as shown in Figure 1. Therefore, it is of great significance to study the influence of the accumulator's passive involvement in electro-hydraulic proportion control.

Experts have conducted many basic studies on accumulators, mainly focusing on noise reduction and energy-saving aspects. To achieve noise reduction, a bladder-type accumulator in coal mine machinery is used

\footnotetext{
* e-mail: 157500083@qq.com
}

to reduce high flow capacity $(2000 \mathrm{~L} / \mathrm{min})$ and load impact [4]. Simulations show that the peak pressure fluctuation (5 MPa) can be eliminated. Additionally, Yang and coworkers [5] show that the accumulator can suppress the water hammer phenomena of hydraulic steering systems and prove that the suppression effect on the water hammer is optimized when the inherent frequency of the water accumulator is equal to or close to the frequency of the water hammer. In references [6-12], hydraulic potential energy regenerative vehicles are designed to reduce the vibration amplitude of vehicles on rough roads and decrease the structural noise. The motor location, the hole area of the valve, the inner diameter of pipelines, and the accumulator pressure are key factors contributing to suspension performance. By combining the accumulator's pressure signal and PID algorithm, there is a better effect in the aspect of reducing vibration and pitching movement. The accumulator plays an important role of adjusting rigidity in vehicle suspension. The whole system can have a higher modal stiffness and damping coefficient by changing the accumulator's inflation pressure. If the mode is applied to a valve-controlled motor system, the motor can achieve constant velocity [8]. To address energy conservation, the accumulator is integrated to develop a five-valve flow control and is combined with a new algorithm to keep accurate motion-tracking performance of the hydraulic cylinder and reduce energy consumption [13]. According to 

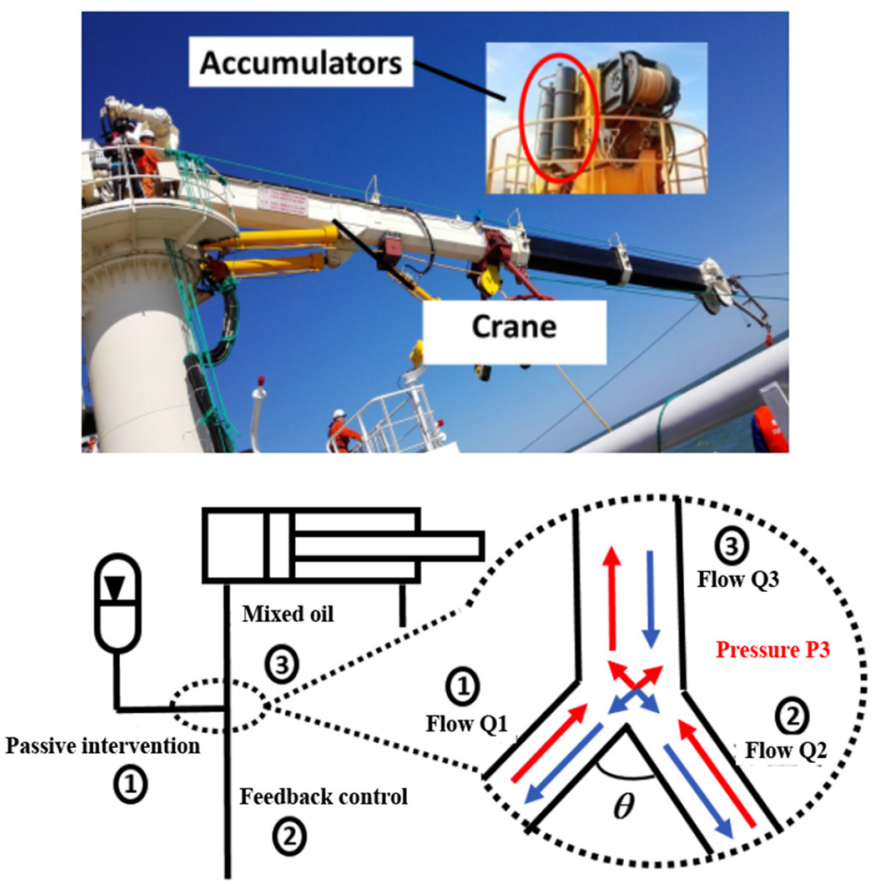

Fig. 1. Cylinder's control under the intervention of the accumulator.

modeling and simulation, the accumulator's highest energy conservation rate of potential energy recovery in an electric hydraulic forklift is $36 \%[14,15]$. As a source of auxiliary power, the accumulator improves the complex nonlinear response and control accuracy of valve-controlled motors; AMESIM and Simulink models are adopted to make dynamic simulations [16]. A kilowatt-level hydraulic buck converter is designed, and it is proved by experiments that the accumulator has an obvious role in guaranteeing system linearity and reducing energy consumption [17]; wave energy is transformed into potential energy and stored in the accumulator, and the theoretical peak of transformation rate can be up to $27 \%$. However, the overall transformation efficiency of equipment in model prototype tests is low, with a mean value of about $6 \%[18,19]$. In general, the model is effective, and the overall efficiency is low. Cylinders and accumulators are wildly used in excavators [20-23]. The accumulator plays a key role in hydraulic design. Through coupling power output, the overall energy conservation effect can be improved to 10.1\%. Related designs are applied in rock drills [24], scrapers [25], fast-forging presses [26], and other engineering machinery. Some studies replace the throttle valve, unloading valve, and fuel tank with an accumulator; in this way, the energy regeneration efficiency of the system is $44 \%$ or even higher [27-33]. Another study uses a variable area gas piston with a fixed cylinder area, and the results reveal that the constant pressure accumulator provides a $16 \%$ improvement in energy density over a conventional accumulator [34].

Most literature regarding accumulators focuses on the energy-saving and vibration-reduction characteristics of accumulators. The effect of passive intervention of accumulators on the valve-controlled cylinder oil is rarely reported. Accumulators are often used in applications where the cylinder moves slowly, but wave compensation requires that the cylinder can conduct a fast response. Furthermore, there are several problems with wave compensation. First, the accumulator will face an inertia delay caused by the cylinder's outstretch and frequent retraction. Second, the hydraulic components' nonlinearity and oil pressure hysteresis can also lead to the delayed response of the accumulator. Third, the components' parameters are uncertain. As a result, the angle error cannot be compensated in time. The rapid increase of compensation signal can easily lead to another overshoot during the next time period.

Our contribution is to establish the coupling dynamic model of the valve-controlled cylinder with an accumulator. Comparative analyses, simulations, and experiments are conducted to study the accumulator's influence on electro-hydraulic proportional control. Finally, the compensation method is presented and verified.

\section{Dynamic model}

The crane is fixed on the ship and the telescopic arm outstretches from the ship. The wave influences the ship, leading to rotation in three directions, and the luffing mechanism compensates the impact of the rotation in the $Z$ direction. The hydraulic system is shown in Figure 2.

The accumulator and valve provide oil together into the rodless cavity at the outstretch stage, and the oil from the rod cavity returns to the tank through the balance valve. The maximum work pressure of the accumulator can be adjusted by changing the opening pressure of the sequential valve. The oil from the rodless cavity flows into the accumulator at the retracting stage.

\subsection{Valve's flow equation}

In the hydraulic system, the flow $\left(Q_{L}\right)$ is related to the pressure $\left(P_{L}\right)$ and the spool displacement $\left(X_{V}\right): Q_{L}=f\left(x_{v}, P_{L}\right)$. The following assumptions are made: (1) the valve is an ideal positive-opening four-way slide valve and the four orifices are matching and symmetrical, (2) the valve is always working close to its working position, and (3) the fluid cannot be compressed. The valve's flow equation is shown in equation (1) [35]:

$$
q_{1}=C_{d} \cdot w\left(U+x_{v}\right) \sqrt{\frac{2}{\rho}\left(p_{S}-p_{1}\right)},
$$

where $q_{1}$ denotes the oil flow from the valve to the rodless cavity, $\mathrm{m}^{3} / \mathrm{s} ; C_{d}$ denotes the flow coefficient of the valve; $w$ denotes the valve area gradient, $\mathrm{m}^{2} / \mathrm{m} ; U$ denotes the open size of the valve at zero position, $m ; x_{v}$ denotes the displacement of the valve core, $m$; $\rho$ denotes the oil density, $\mathrm{kg} / \mathrm{m}^{3} ; p_{s}$ denotes the system pressure, $\mathrm{N} / \mathrm{m}^{2} ;$ and $p_{1}$ denotes the rodless cavity's pressure, $\mathrm{N} / \mathrm{m}^{2}$. 


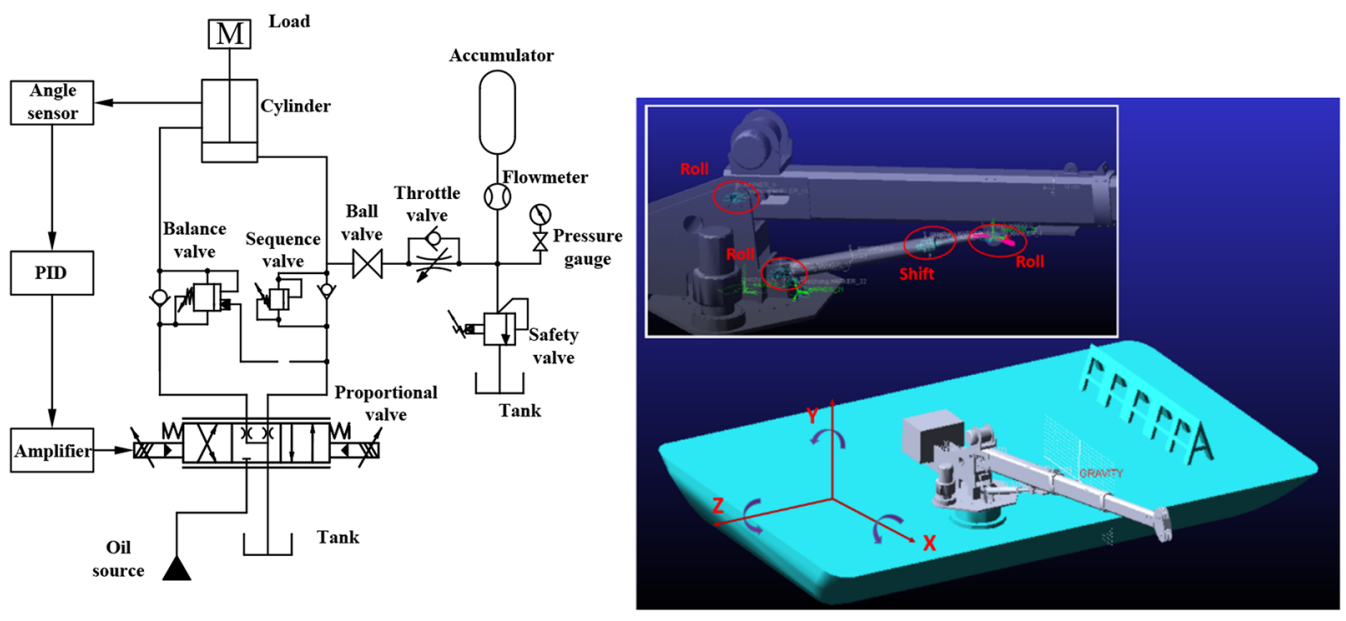

(a)
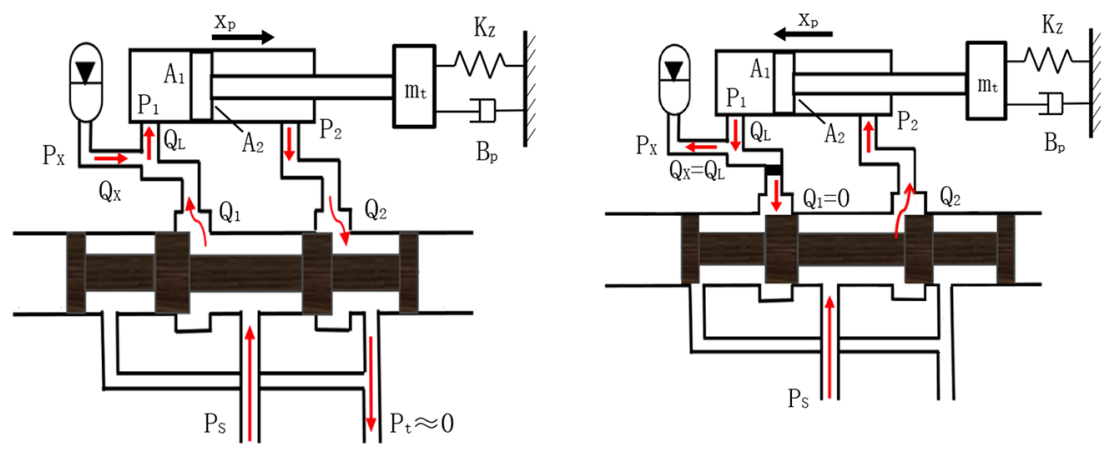

(b)

Fig. 2. (a) Hydraulic scheme. (b) The four-way slide valve and the accumulator connection schematic diagram: (left) outstretch stage, retracting stage (right).

Then, the linearization method can be used to linearize the equation $Q_{L}=f\left(x_{v}, P_{L}\right)$ to obtain equation (2):

$$
Q_{1}=K_{q 1} X_{v}-K_{c 1} P_{1}
$$

where $K_{q 1}$ denotes the flow-displacement gain coefficient of the rodless cavity, $\mathrm{m}^{2} / \mathrm{s}$; and $K_{c 1}$ denotes the flow-pressure gain coefficient of the rodless cavity, $\mathrm{m}^{5} /(\mathrm{s} \cdot \mathrm{N})$.

Equations (3) and (4) can be deduced by taking the derivative of equation (1).

$$
\begin{gathered}
K_{q 1}=C_{d} \cdot w \sqrt{\frac{2}{\rho}\left(p_{S}-p_{10}\right)}, \\
K_{c 1}=\frac{C_{d} \cdot w \cdot U}{\sqrt{2 \rho\left(p_{S}-p_{10}\right)}},
\end{gathered}
$$

where $P_{10}$ denotes the initial pressure of the rodless cavity, $\mathrm{N} / \mathrm{m}^{2}$. (5).

The flow equation of the rod cavity is shown in equation

$$
q_{2}=C_{d} \cdot w\left(U+x_{v}\right) \sqrt{\frac{2 \cdot\left(p_{2}-p_{t}\right)}{\rho}},
$$

where $q_{2}$ denotes the oil flow from the valve to the rod cavity, $\mathrm{m}^{3} / \mathrm{s} ; p_{2}$ denotes the pressure of the rod cavity, $\mathrm{N} / \mathrm{m}^{2} ; p_{t}$ denotes the return oil pressure, $\mathrm{N} / \mathrm{m}^{2} ;$ and $p_{t} \approx 0$.

By applying linearization on equation (5), equation (6) can be obtained:

$$
Q_{2}=K_{q 2} X_{v}+K_{c 2} P_{2}
$$

By taking the derivative of equation (5), equations (7) and (8) can be deduced.

$$
\begin{gathered}
K_{q^{2}}=C_{d} \cdot w \sqrt{\frac{2 p_{20}}{\rho}} \\
K_{c^{2}}=\frac{C_{d} \cdot w \cdot U}{\sqrt{2 \rho \cdot p_{20}}}
\end{gathered}
$$

\subsection{Flow continuity equation of valve-controlled cylinder}

The flow continuity equation of the rodless cavity is shown in equation (9), and its Laplace transformation is shown in 
equation (10).

$$
\begin{gathered}
q_{L}=q_{X}+q_{1}=A_{1} \cdot \frac{d x_{P}}{d t}+C_{i}\left(p_{1}-p_{2}\right)+\frac{V_{1}}{\beta_{e}} \cdot \frac{d p_{1}}{d t}, \\
Q_{L}=Q_{X}+Q_{1}=A_{1} \cdot s \cdot X_{P}+C_{i}\left(P_{1}-P_{2}\right)+\frac{V_{1}}{\beta_{e}} \cdot s \cdot P_{1},
\end{gathered}
$$

where $Q_{L}$ denotes the total flow of the rodless cavity of the cylinder, $\mathrm{m}^{3} / \mathrm{s} ; Q_{X}$ denotes the oil flow from the accumulator, $\mathrm{m}^{3} / \mathrm{s} ; X_{P}$ denotes the displacement of the pistol, $\mathrm{m} ; C_{i}$ denotes the internal leakage coefficient, $\mathrm{m}^{5} /(\mathrm{N} \cdot \mathrm{s}) ; V_{1}$ denotes the total volume of the rodless chamber (containing the connecting pipe and the inside of the cylinder), $\mathrm{m}^{3}$; and $\beta_{e}$ denotes the liquid Bulk Elastic Modulus, $\mathrm{N} / \mathrm{m}^{2}$.

By combining equations (2) and (10), equation (11) can be obtained.

$$
\left(K_{c 1}+C_{i}+\frac{V_{1}}{\beta_{e}} \cdot s\right) P_{1}-Q_{x}=K_{q 1} \cdot X_{v}-A_{1} \cdot s \cdot X_{P}+C_{i} \cdot P_{2} .
$$

The flow continuity equation of the rod cavity is shown in equation (12), and its Laplace transformation is shown in equation (13).

$$
\begin{gathered}
q_{2}=A_{2} \cdot \frac{d x_{P}}{d t}+C_{i}\left(p_{1}-p_{2}\right)-C_{e} \cdot p_{2}-\frac{V_{2}}{\beta_{e}} \cdot \frac{d p_{2}}{d t}, \\
Q_{2}=A_{2} \cdot s \cdot X_{P}+C_{i}\left(P_{1}-P_{2}\right)-C_{e} \cdot P_{2}-\frac{V_{2}}{\beta_{e}} \cdot s \cdot P_{2},
\end{gathered}
$$

where $C_{e}$ denotes the external leakage coefficient, $\mathrm{m}^{5} /(\mathrm{N} \cdot \mathrm{s})$; and $V_{2}$ denotes the total volume of the rod chamber (containing the connecting pipe and the inside of the cylinder), $\mathrm{m}^{3}$.

By combining equations (6) and (13), equation (14) can be obtained.

$$
\left(K_{c 2}+C_{i}+C_{e}+\frac{V_{2}}{\beta_{e}} \cdot s\right) P_{2}=-K_{q 2} \cdot X_{v}+A_{2} \cdot s \cdot X_{P}+C_{i} \cdot P_{1} .
$$

\subsection{Dynamic equation of the cylinder's piston rod}

The force equation of the cylinder's piston rod is shown in equation (15), and its Laplace transformation is shown in equation (16).

$$
\begin{aligned}
& P_{1} \cdot A_{1}-P_{2} \cdot A_{2}=m_{t} \frac{d^{2} x_{p}}{d t^{2}}+B_{P} \cdot \frac{d x_{P}}{d t}+K_{z} \cdot x_{P}+F_{L}, \\
& P_{1} \cdot A_{1}-P_{2} \cdot A_{2}=m_{t} \cdot X_{p} \cdot s^{2}+B_{P} \cdot X_{P} \cdot s+K_{z} \cdot X_{P}+F_{L},
\end{aligned}
$$

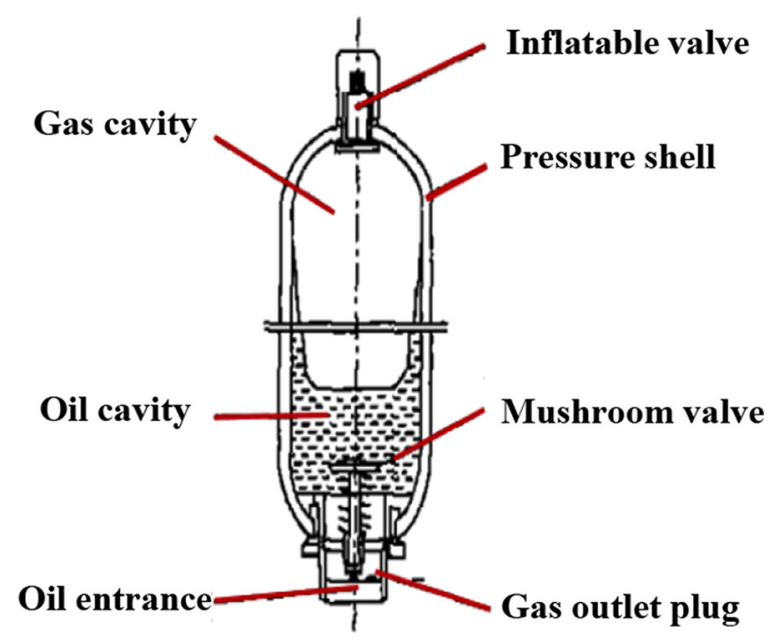

(a)

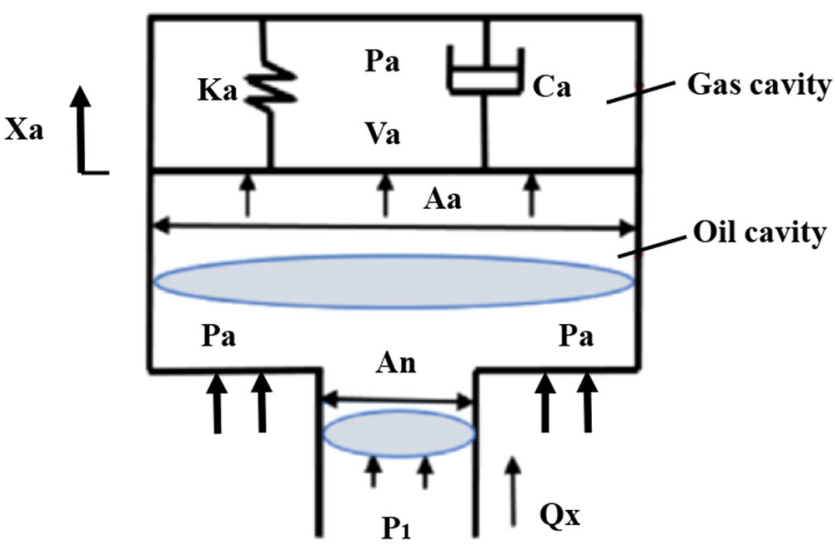

(b)

Fig. 3. Accumulator's dynamic model. (a) Bladder accumulator. (b) Simplified model.

where $m_{t}$ denotes the mass of the piston, $\mathrm{kg} ; B_{P}$ denotes the viscosity damping coefficient, $(\mathrm{N} \cdot \mathrm{s}) / \mathrm{m} ; K_{z}$ denotes the spring stiffness, $\mathrm{N} / \mathrm{m}$; and $F_{L}$ denotes the external load, $N$.

\subsection{Dynamic equation of the accumulator}

The bladder accumulator's structure [36] and simplified force model are shown in Figure 3.

Equation (17) is derived from the ideal gas equation $p_{0 a} \cdot V_{0 a}^{k}=p_{a} \cdot V_{a}^{k}$, where $k$ denotes the gas variable index, $k=1.4 ; P_{0 a}$ denotes the initial pressure of the accumulator, $\mathrm{N} / \mathrm{m}^{2}$; and $V_{0 a}$ denotes the initial volume of the accumulator, $\mathrm{m}^{3}$.

$$
p_{a} V_{a}^{k}=p_{0 a} V_{0 a}^{k}+V_{0 a}^{k} \cdot\left(p_{a}-p_{0 a}\right)+k \cdot p_{0 a} V_{0 a}^{k-1} \cdot\left(V_{a}-V_{0 a}\right) .
$$

$P_{a}=(k+\mathbf{1}) \cdot P_{0 a}-k \cdot P_{0 a} \cdot V_{0 a}^{-1} \cdot V_{a}=\mathbf{2 . 4} P_{0 a}-\mathbf{1 . 4} P_{0 a} \cdot V_{0 a}^{-1} \cdot V_{a}$. 


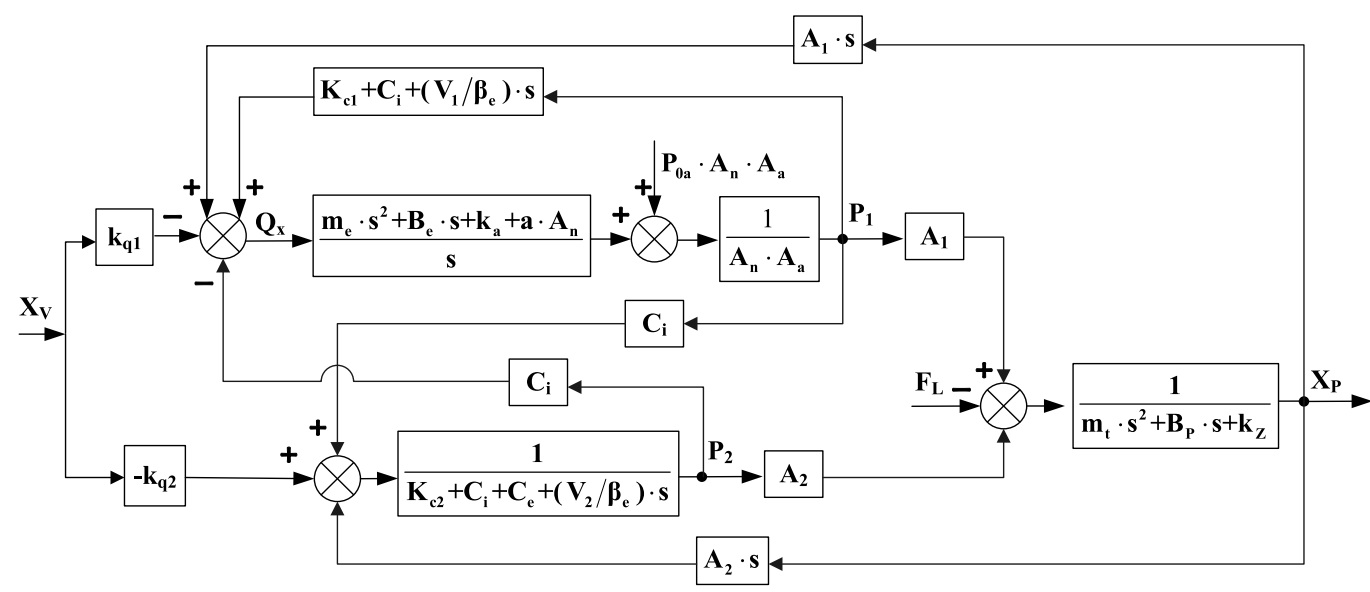

Fig. 4. Block diagram of power elements.

By the definition $a=\mathbf{1 . 4} P_{0 a} \cdot V_{0 a}{ }^{-1} \cdot A_{a}$, equation (18) can be simplified as equation (19) with $V_{a}=V_{0 a}-x_{a} \cdot A_{a}$.

$$
P_{a}=P_{0 a}+a \cdot X_{a} .
$$

The force equation of the oil in the accumulator is shown in equation (20), and its Laplace transformation is shown in equation $(21)$.

$$
\begin{gathered}
\left(p_{1}-p_{a}\right) A_{n}=m_{e} \cdot \frac{d^{2} x_{a}}{d t^{2}}+B_{e} \cdot \frac{d x_{a}}{d t}+k_{a} \cdot x_{a}, \\
\left(P_{1}-P_{a}\right) A_{n}=m_{e} \cdot s^{2} \cdot X_{a}+B_{e} \cdot s \cdot X_{a}+k_{a} \cdot X_{a},
\end{gathered}
$$

where $A_{n}$ denotes the cross-section area of the pipeline, $\mathrm{m}^{2} ; A_{a}$ denotes the cross-section area of the accumulator, $\mathrm{m}^{2} ; V_{a}$ denotes the gas cavity volume of the accumulator, $\mathrm{m}^{3} ; P_{a}$ denotes the gas cavity pressure of the accumulator, $\mathrm{N} / \mathrm{m}^{2} ; m_{e}$ denotes the quality of oil in the accumulator, $\mathrm{kg} ; B_{e}$ denotes the equivalent damping coefficient of oil, $(\mathrm{N} \cdot \mathrm{s}) / \mathrm{m}$; and $K_{a}$ denotes the stiffness coefficient of gas, $\mathrm{N} / \mathrm{m}$.

\subsection{Flow continuity equation of the accumulator}

The output flow of the accumulator is equal to the volume change rate, so equation (22) is obtained. Its Laplace transformation is shown in equation (23):

$$
\begin{gathered}
q x=\frac{d x_{a}}{d t} \cdot A_{a} . \\
Q_{X}=s \cdot X_{a} \cdot A_{a} .
\end{gathered}
$$

Equation (24) can be obtained by combining equations (19), (21), and (23).

$A_{a} \cdot A_{n} \cdot P_{1}=\frac{1}{s} \cdot Q_{X} \cdot\left(m_{e} \cdot s^{2}+B_{e} \cdot s+k_{a}+a \cdot A_{n}\right)+P_{0 a} \cdot A_{a} \cdot A_{n}$.

\section{Simulation analysis}

Equations (11), (14), (16), and (24) are utilized to establish the block diagram of power elements. Figure 4 shows the working process from the control signal to the cylinder's piston rod displacement in Simulink software. The simulation parameters are shown in Table 1.

The stiffness coefficient of gas $\left(K_{a}\right)$ is relative to the current cavity volume of the accumulator:

$$
K_{a}=\lim _{\Delta V \rightarrow 0}\left(-\frac{\Delta P}{\Delta V} \cdot A_{a}^{2}\right)=k \cdot P_{0 a} \cdot V_{0 a}^{k} \cdot A_{a}^{2} \cdot V^{-k-1} .
$$

If $V$ is $4.4 L$ at the stable working position, then $K_{a}=4.03 \times 10^{5} \mathrm{~N} / \mathrm{m}$.

\subsection{Analysis of step signal response}

A positive step signal is assigned to simulate the protruding condition. The simulation results from the oscilloscope are shown in Figure 5.

At the beginning, the cylinder outstretches rapidly due to the electro-hydraulic valve and the accumulator's powered oil. The consumed time with the accumulator is $0.25 \mathrm{~s}$, which is less than the consumed time without the accumulator $(2 \mathrm{~s})$. When the cylinder outstretches to the end without the accumulator, the pressure of the rodless cavity rises quickly to the threshold value. In contrast, the pressure with the accumulator rises slowly.

Conclusion: In the outstretch phase, the accumulator's oil flow is nonlinear. The boom angle changes quickly in the beginning and then tends to be stable. The slowly changing pressure with the accumulator leads to the velocity fluctuation.

A negative step signal is assigned to simulate the retracting movement. The simulation results from the oscilloscope are shown in Figure 6.

In the step retraction movement, the accumulator adsorbs the oil due to the rising oil pressure. Because of the same powered oil, the boom angle curves in the two situations are same. In the condition without the accumulator, the pressure of the rodless cavity reaches the threshold value of the sequence valve, and then the oil flows into the tank. 


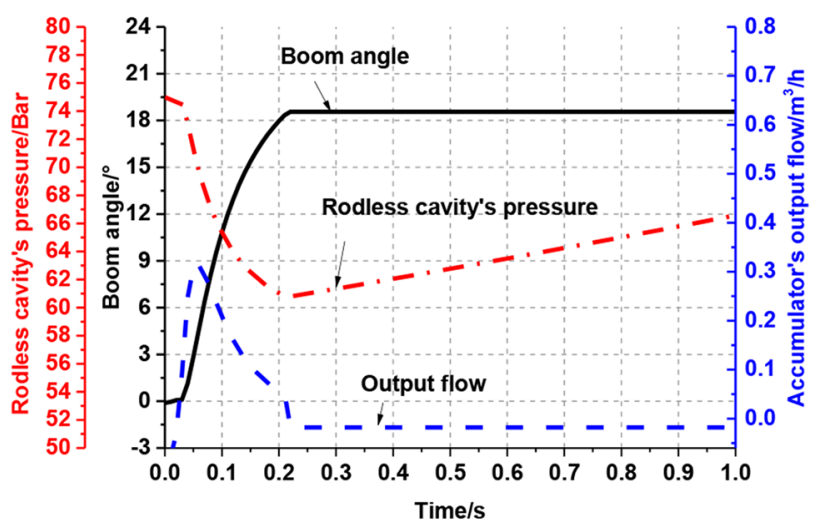

(a)
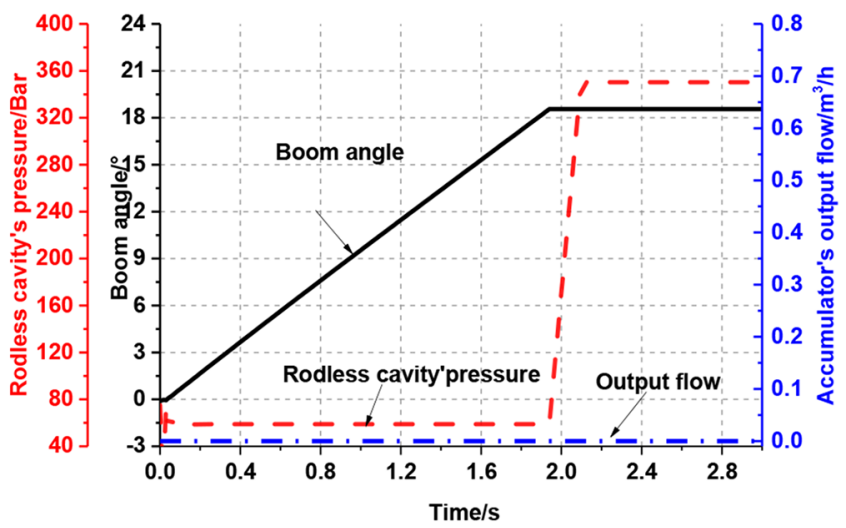

(b)

Fig. 5. Step response simulation at the outstretch stage. (a) Corresponding with accumulator. (b) Corresponding without accumulator.

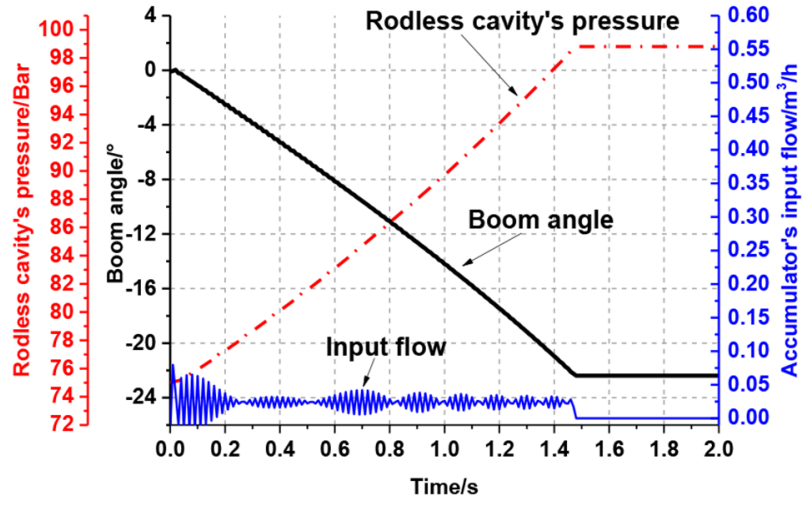

(a)

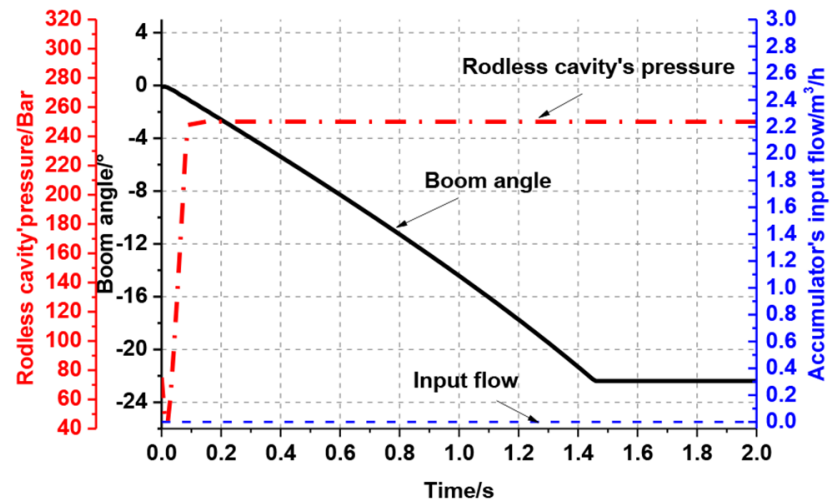

(b)

Fig. 6. Step response at the retracting stage. (a) Corresponding with accumulator. (b) Corresponding without accumulator.

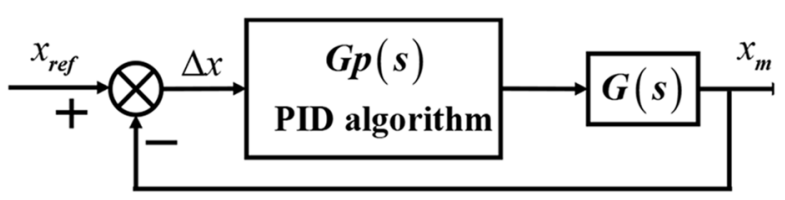

Fig. 7. Block diagram of the PID control method.

Conclusion: In the cylinder retraction phase, the accumulator has no obvious effect on the cylinder movement. The pressure of the rodless cavity rises slowly, and the accumulator adsorbs the oil until the pressure reaches the sequence valve's threshold value.

\subsection{Analysis of PID control response}

The process of the valve-controlled cylinder system with the PID algorithm is shown in Figure 7, where $G p(s)$ is the algorithm, which is used to get the control signal, and $\Delta x$ is the deviation between the cylinder's actual displacement $\left(x_{m}\right)$ and given displacement $\left(x_{\text {ref }}\right)$, that is, $\Delta x=x_{\text {ref }}-x_{m}$.
The step signal is set, and the cylinder's displacement is shown in Figure 8.

The cylinder fluctuates around the target location and tends to be stable eventually. By comparison, the deviation and consumed time in the condition with the accumulator is larger than in the condition without the accumulator.

\subsection{Analysis of wave compensation response in one period}

The ship sways periodically with the character of the sinecosine rule. In order to keep the boom angle stable, the cylinder's trajectory also needs to adhere to the sine-cosine rule to compensate for the ship's swaying. In the $0-0.5$ period, the cylinder outstretches with the sine-cosine character; in the $0.5-1$ period, the cylinder extracts with the sine-cosine character. The wave compensation curves in one period under the PID algorithm are shown in Figures 9 and 10.

In the outstretch stage, the wave compensation movement with the accumulator shows higher deviation fluctuation, but the vibration frequency is lower. 

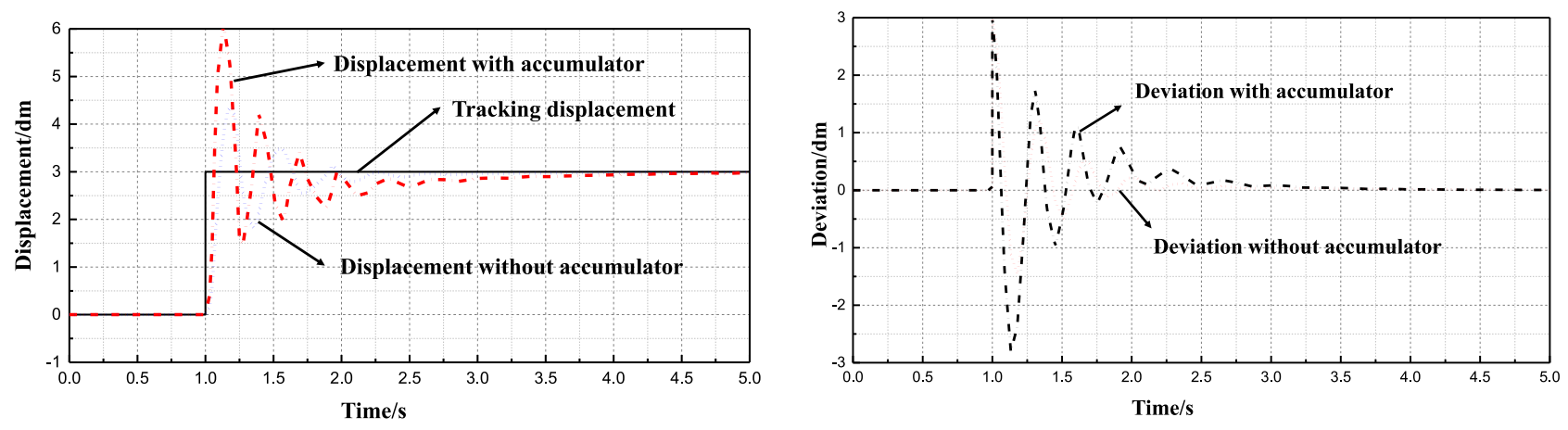

Fig. 8. Displacement simulation of PID response.

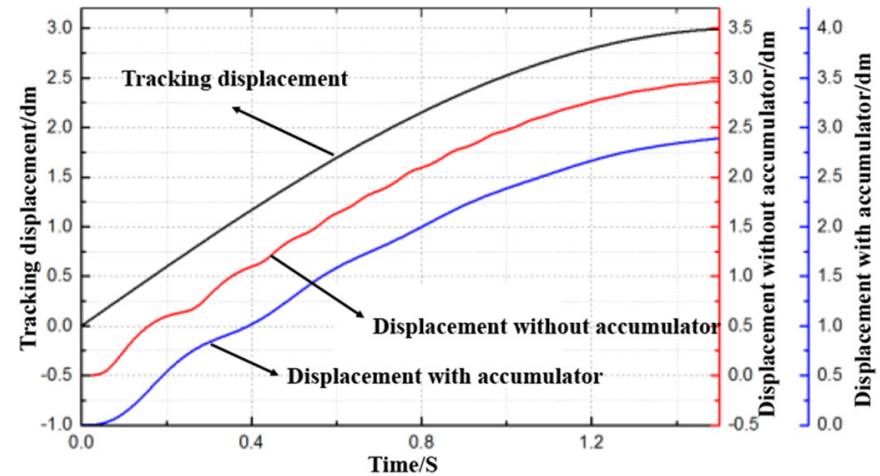

(a)

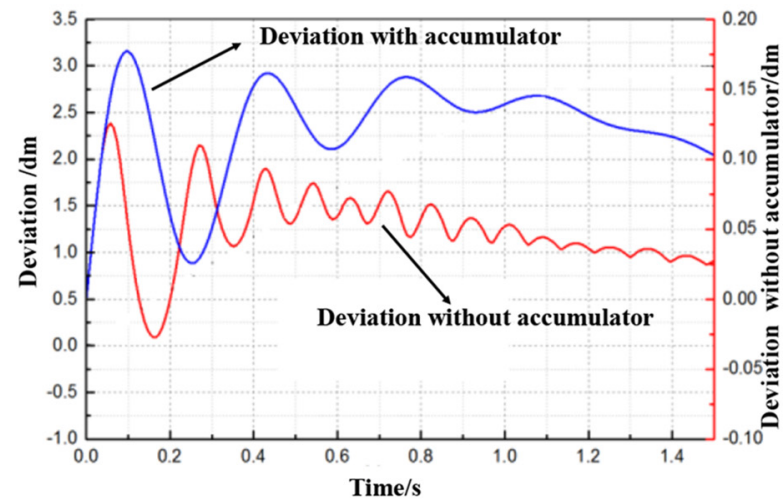

(b)

Fig. 9. Wave compensation curves during stretching phase. (a) Cylinder tracking trajectory. (b) Deviation fluctuation curve.

In the retracting stage, the wave compensation curves are both smooth and show no obvious deviation fluctuation.

\section{Experimental verifications}

\subsection{Introduction of experimental equipment}

The crane, as shown in Figure 11, includes the luffing mechanism, the telescopic mechanism, the rotary mechanism, and the hoist mechanism.

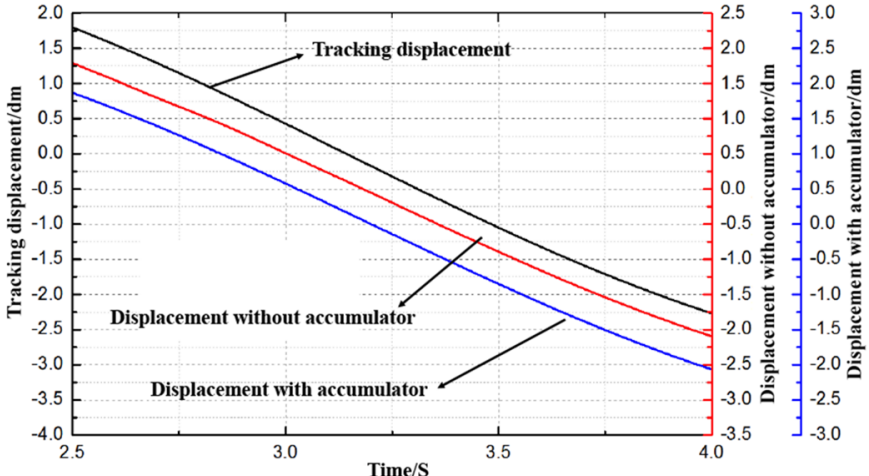

(a)

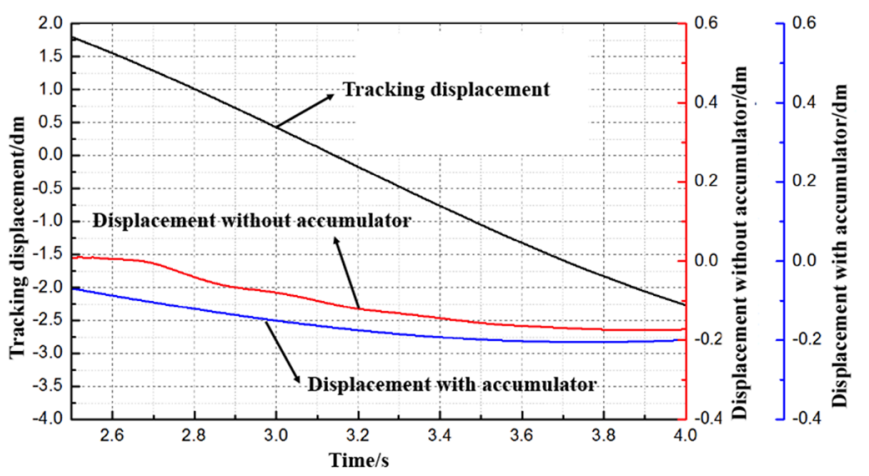

(b)

Fig. 10. Wave compensation curves during the retracting phase. (a) Oil cylinder tracking trajectory. (b) Deviation fluctuation curve.

The PLC outputs a $4-20 \mathrm{~mA}$ current signal, which is used to control the valve through a proportional amplifier. The angle and displacement sensors are applied to reflect the cylinder's movements. The parameters of the equipment are shown in Table 2.

The designed control interface is shown in Figure 12. It can display the current angle and the set angle and has the function of reading and writing parameters. The data are recorded in real time at a rate of 5 data points per second. 


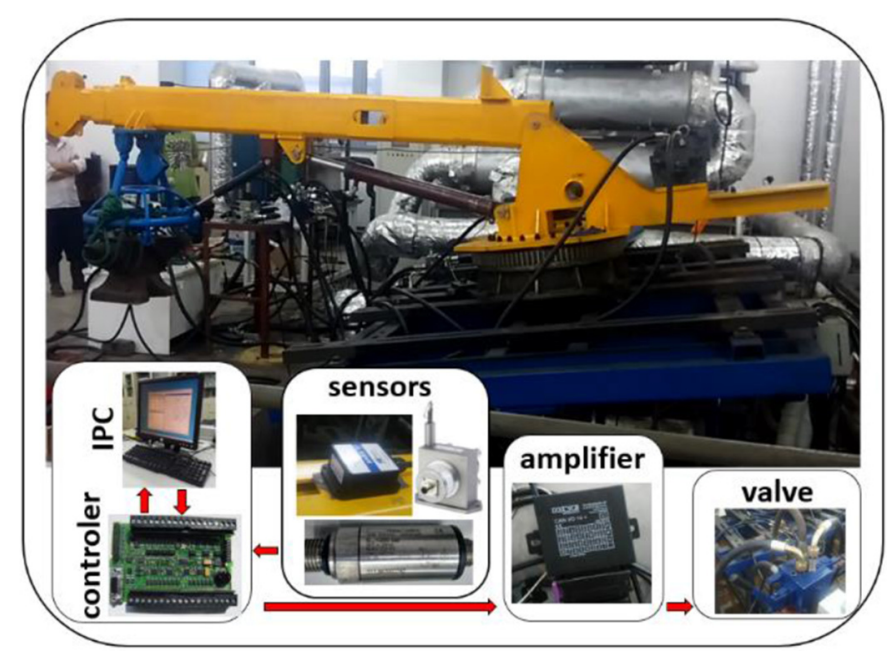

Fig. 11. Laboratory equipment.

\subsection{Experimental strategy and data analysis}

The experimental strategy is divided into three steps. First, the threshold value of the sequence valve is set to make the accumulator work in a proper condition. Second, the step signal is applied, and the responses are compared in these two conditions to verify the influence of the accumulator. Third, the swing table is wobbled to simulate harsh sea conditions, the compensation experiments are conducted, and the influence of the accumulator is studied in wave compensation movement.

\subsubsection{The external conditions of the accumulator}

The working pressure range of the accumulator is related to multiple factors, such as charging pressure, accumulator volume, pipe diameter, and piston position. We adjust the valves' working pressure and record the process of oil absorption and release, as shown in Figure 13. As the cylinder retracts from $25^{\circ}$ to $-8^{\circ}$, the accumulator absorbs energy. The pressure of the rodless cavity rises from

Table 1. Simulation parameters.

\begin{tabular}{llll}
\hline Parameter name & Description & Value & Units \\
\hline$A_{1}$ & Action area of rodless cavity & $6.36 \times 10^{-3}$ & $\mathrm{~m}^{2}$ \\
$A_{2}$ & Action area of rod cavity & $4.77 \times 10^{-3}$ & $\mathrm{~m}^{2}$ \\
$m_{t}$ & Mass of the piston & 7.0 & $\mathrm{Kg}$ \\
$B_{P}$ & Viscosity damping coefficient & 0.2 & $(\mathrm{~N} \cdot \mathrm{s}) / \mathrm{m}$ \\
$K z$ & Spring stiffness & $8.0 \times 10^{2}$ & $\mathrm{~N} / \mathrm{m}$ \\
$F_{L}$ & External load & $3.92 \times 10^{4}$ & $\mathrm{~N}$ \\
$V_{1}$ & Total volume of rodless chamber & $2.5 \times 10^{-3}$ & $\mathrm{~m}^{3}$ \\
$V_{2}$ & Total volume of rod chamber & $2.03 \times 10^{-3}$ & $\mathrm{~m}^{3}$ \\
$\beta_{e}$ & Liquid bulk elastic modulus & $1.7 \times 10^{9}$ & $\mathrm{~N} / \mathrm{m}^{2}$ \\
$C_{i}$ & Internal leakage coefficient & $5.1 \times 10^{-13}$ & $\mathrm{~m}^{5} /(\mathrm{N} \cdot \mathrm{s})$ \\
$C_{e}$ & External leakage coefficient & $3.0 \times 10^{-13}$ & $\mathrm{~m}^{5} /(\mathrm{N} \cdot \mathrm{s})$ \\
$C_{d}$ & Flow coefficient of valve port & 0.61 & \\
$w$ & Valve area gradient & $3.14 \times 10^{-2}$ & $\mathrm{~m}^{2} / \mathrm{m}$ \\
$U$ & The open size of valve at zero position & $1.0 \times 10^{-3}$ & $\mathrm{~m}$ \\
$\rho_{2}$ & Oil density & $8.5 \times 10^{2}$ & $\mathrm{~kg} / \mathrm{m}^{3}$ \\
$P_{S}$ & System pressure & $8.0 \times 10^{6}$ & $\mathrm{~Pa}$ \\
$P_{0 a}$ & Initial pressure of accumulator & $6.0 \times 10^{6}$ & $\mathrm{~Pa}$ \\
$V_{0 a}$ & Initial volume of accumulator & $6.3 \times 10^{-3}$ & $\mathrm{~m}$ \\
$P_{10}$ & Initial pressure of rodless cavity & $7.5 \times 10^{6}$ & $\mathrm{~Pa}$ \\
$P_{20}$ & Initial pressure of rod cavity & $1.78 \times 10^{6}$ & $\mathrm{~Pa}$ \\
$K_{C 1}$ & Flow-pressure gain coefficient of rodless cavity & $5.4 \times 10^{-11}$ & $\mathrm{~m} / /(\mathrm{N} \cdot \mathrm{s})$ \\
$K_{q 1}$ & Flow gain coefficient of rodless cavity & 0.868 & $\mathrm{~m} / \mathrm{s}$ \\
$K_{C 2}$ & Flow-pressure gain coefficient of rod cavity & $4.1 \times 10^{-11}$ & $\mathrm{~m} 5 /(\mathrm{N} \cdot \mathrm{s})$ \\
$K_{q 2}$ & Flow gain coefficient of rod cavity & 1.1393 & $\mathrm{~m} \mathrm{~m}^{2} / \mathrm{s}$ \\
$A_{n}$ & Cross-sectional area of pipeline & $1.38 \times 10^{-3}$ & $\mathrm{~m} \mathrm{~m}^{2}$ \\
$A_{a}$ & Cross-sectional area of accumulator & $1.13 \times 10^{-2}$ & $\mathrm{~m}$ \\
$m_{e}$ & Quality of oil in accumulator & 1.49 & $\mathrm{~kg}$ \\
$B_{e}$ & Equivalent damping coefficient of oil & 0.2 & $(\mathrm{~N} \cdot \mathrm{s}) / \mathrm{m}$ \\
$K_{a}$ & Stiffness coefficient of gas & & $\mathrm{N} / \mathrm{m}$ \\
\hline & & & \\
\hline
\end{tabular}


$7.56 \times 10^{6} \mathrm{~Pa}$ to $9.28 \times 10^{6} \mathrm{~Pa}$. The accumulator releases the oil in a nonlinear way when the cylinder outstretches. At first, the oil is released quickly, so the curve is very steep, and then the angle-change tends to be smooth. The consumed time is about $6 \mathrm{~s}$.

The color block diagram in Figure 13 shows the relationship among the energy releasing value, external

Table 2. Components' parameters.

\begin{tabular}{lll}
\hline Name & Content & Parameters \\
\hline Crane & Weight, t & 4.8 \\
& Maximum system pressure & 180 \\
Luffing & Maximum operating & 1.5 \\
mechanism & range, m & \\
& Maximum working & 1 \\
& velocity, m/s & \\
& The pitching angle, ${ }^{\circ}$ & -20 to 25 \\
& Maximum lifting weight, t & 1.25 \\
Accumulator & Model type & Bladder \\
& Volume, L & 6.3 \\
& Precharge pressure, Pa & $6.0 \times 10^{6}$ \\
Cylinder & Bore-rod, mm & $90-45$ \\
& Cylinder stroke, mm & 340 \\
Pressure & Range, Pa & $0-60 \times 10^{6}$ \\
sensor & Response time, ms & $<2$ \\
& Accuracy & $0.3 \%$ \\
& Linearity & $\leq 0.5 \%$ \\
Flow sensor & Range, m ${ }^{3} / \mathrm{h}$ & $0.2-1.2$ \\
& Accuracy & $\pm 1 \%$ Range \\
\hline
\end{tabular}

pressure, and cylinder's velocity. The left color block diagram shows that the energy's released velocity is significantly related to the cylinder's outstretch velocity and has no obvious relationship with pressure. The color block diagram on the right shows that the energyabsorbing velocity is significantly related to both the pressure and the velocity of the cylinder.

Conclusion: The working pressure of accumulator is related to the volume of the accumulator and the precharge pressure. The precharge pressure should be $80 \%$ of the minimum working pressure. The sequence valve's threshold value should be higher than the largest working pressure of the accumulator. The volume of the accumulator should be larger than the volume of the cylinder rodless cavity.

\subsubsection{Periodic step control analysis}

The following steps are conducted in two conditions. (1) Apply a negative step signal to make the cylinder conduct retraction movement. (2) Apply a zero signal when the boom angle drops down to $-8^{\circ}$, and then wait for $2 \mathrm{~s}$. (3) Apply a positive signal to make the cylinder conduct outstretch movement. (4) Apply a zero signal when the boom angle rises up to $25^{\circ}$, and then wait for $2 \mathrm{~s}$. The response curves are recorded in Figures 14 and 15. The step response appears to have a periodic character. Hence, one period is divided into four stages, and each stage is studied separately.

\section{Retraction stage}

The retraction movement of the cylinder is shown in Figure 16. When the accumulator is shut down, the pressure increases rapidly to the stable state within $1 \mathrm{~s}$, and the curve below indicates that the boom angle changes smoothly. By comparison, when the

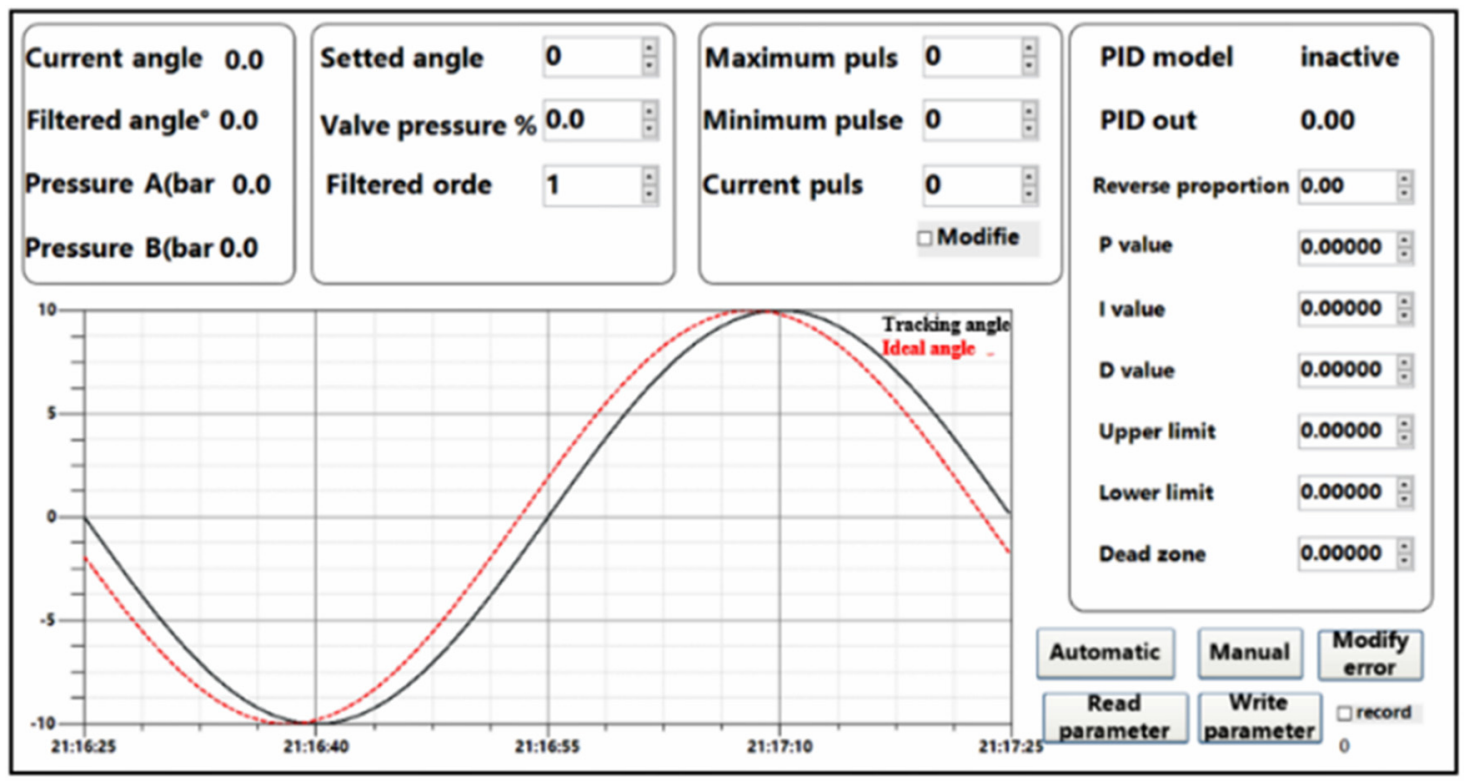

Fig. 12. Control interface. 

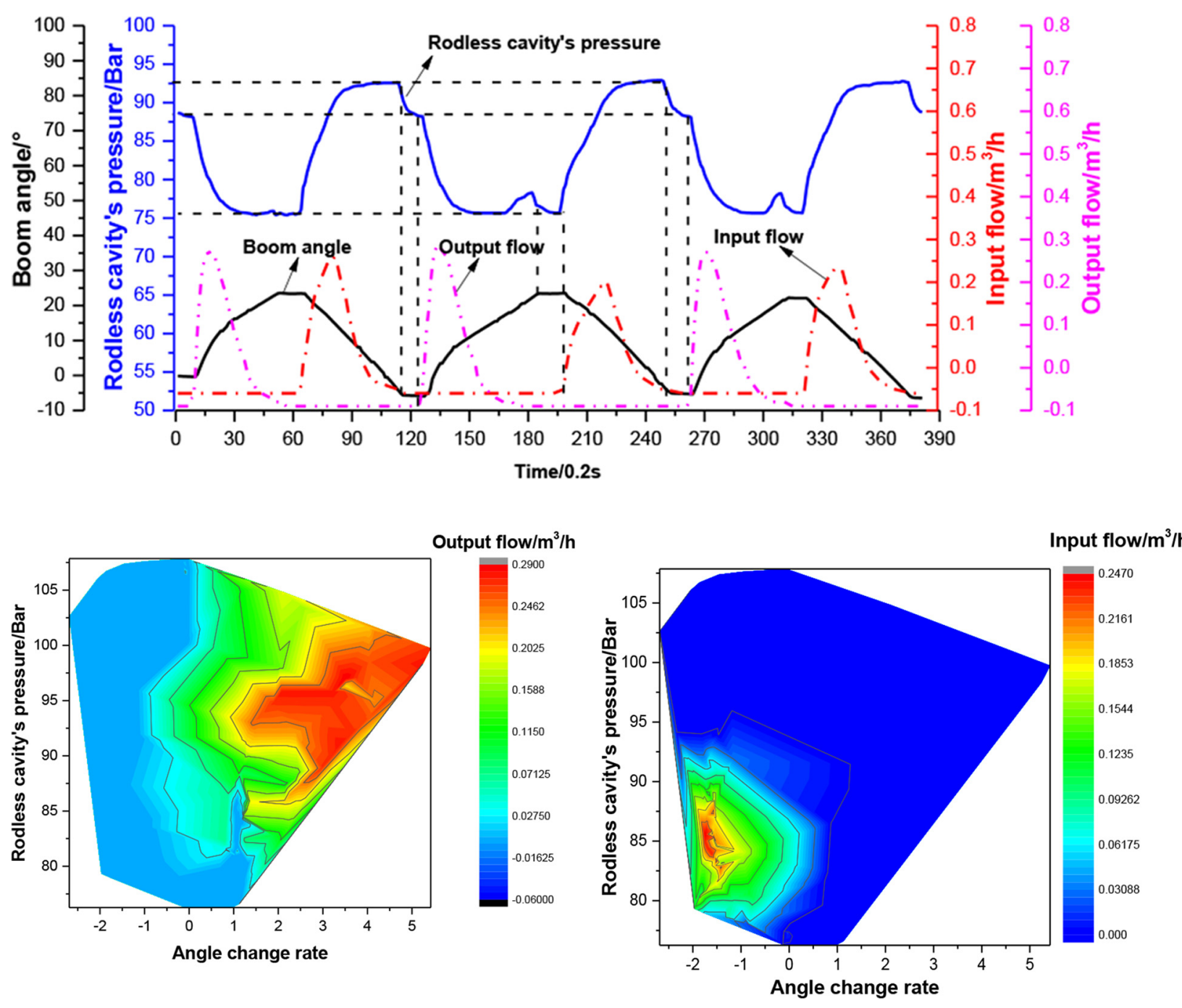

Fig. 13. Accumulator external conditions test.

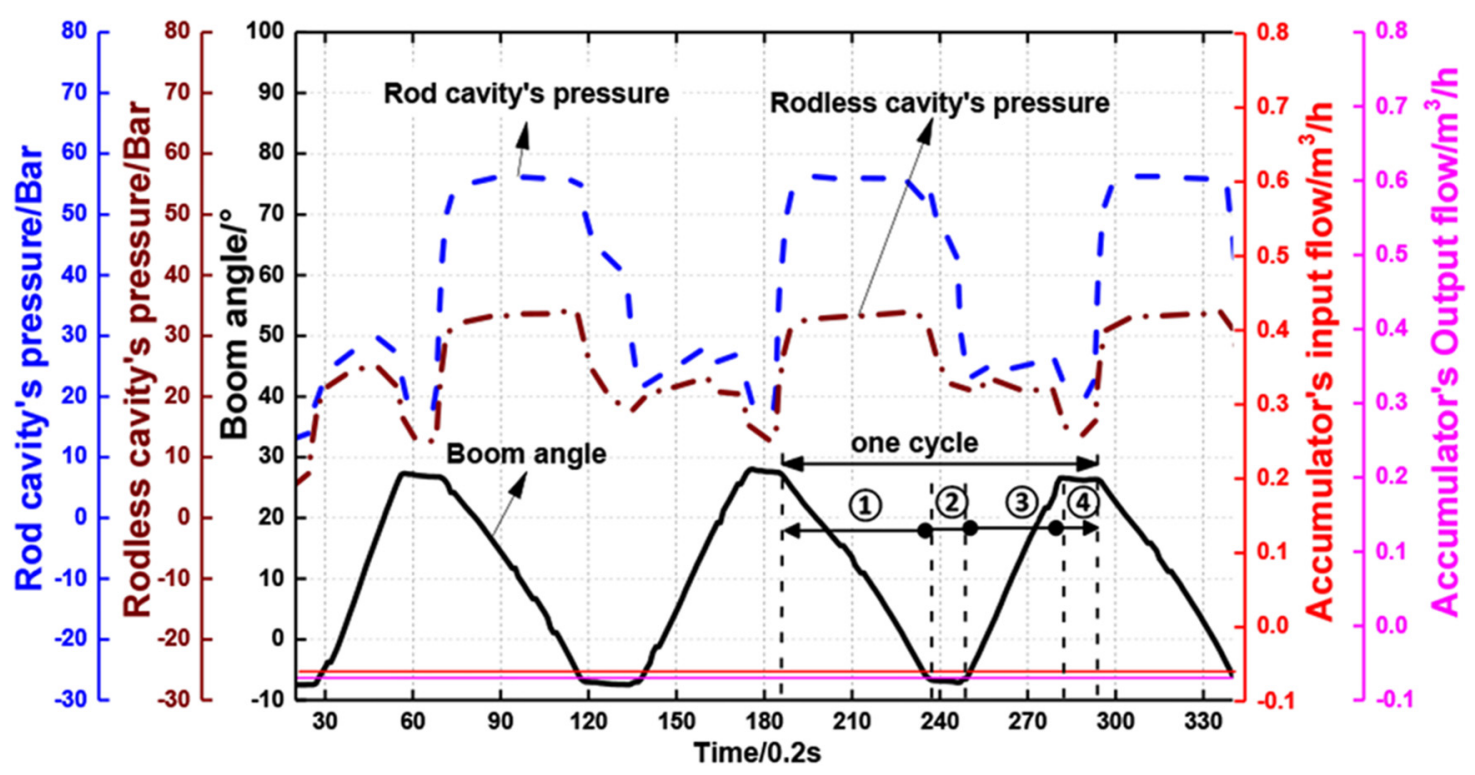

Fig. 14. Step control without accumulator. 


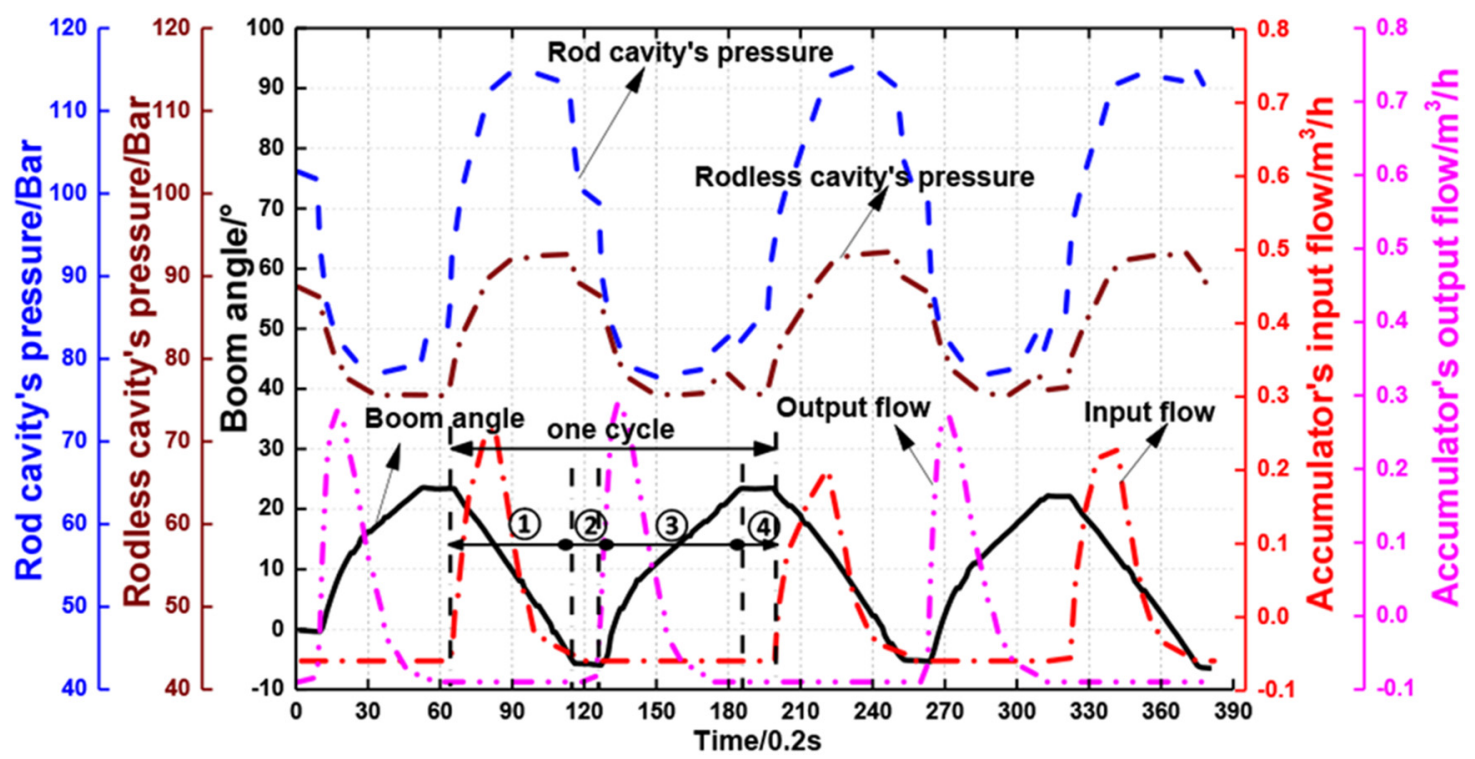

Fig. 15. Step control with accumulator.

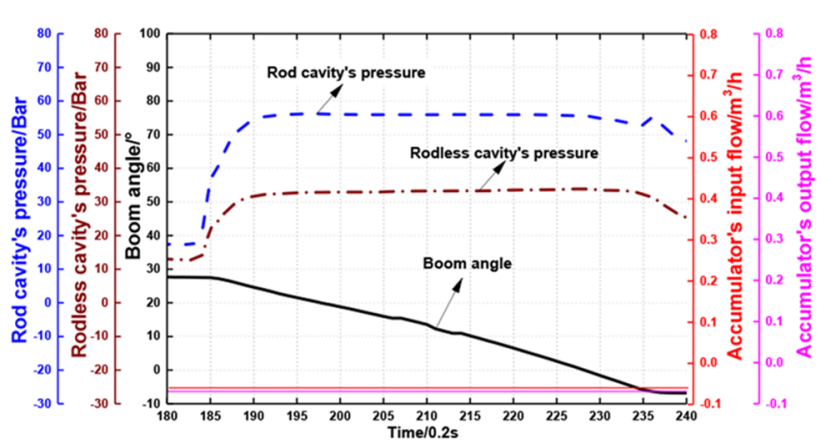

(a)

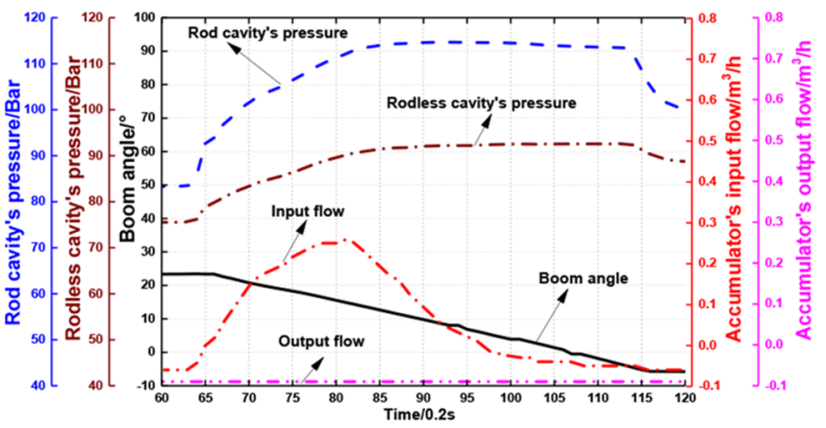

(b)

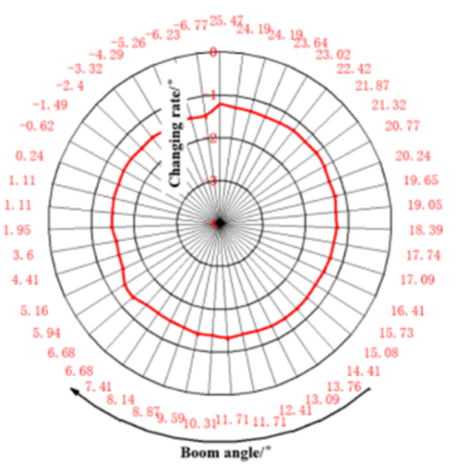

(c)

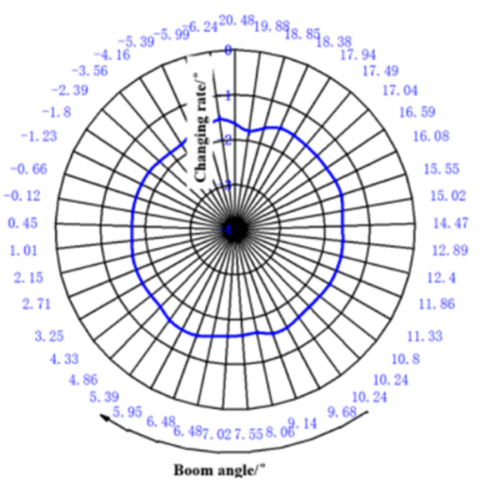

(d)

Fig. 16. Cylinder's retracted stage. (a) Corresponding without accumulator. (b) Corresponding with accumulator. (c) Angle changing rate without accumulator. (d) Angle changing rate with accumulator.

accumulator is started, the pressure increases slowly to the stable state within $5 \mathrm{~s}$, and the angle changes smoothly as shown in the right curve below.
Conclusion: In the retraction stage, the pressure curve changes from step state to smooth state after the accumulator is added. The accumulator reduces the 


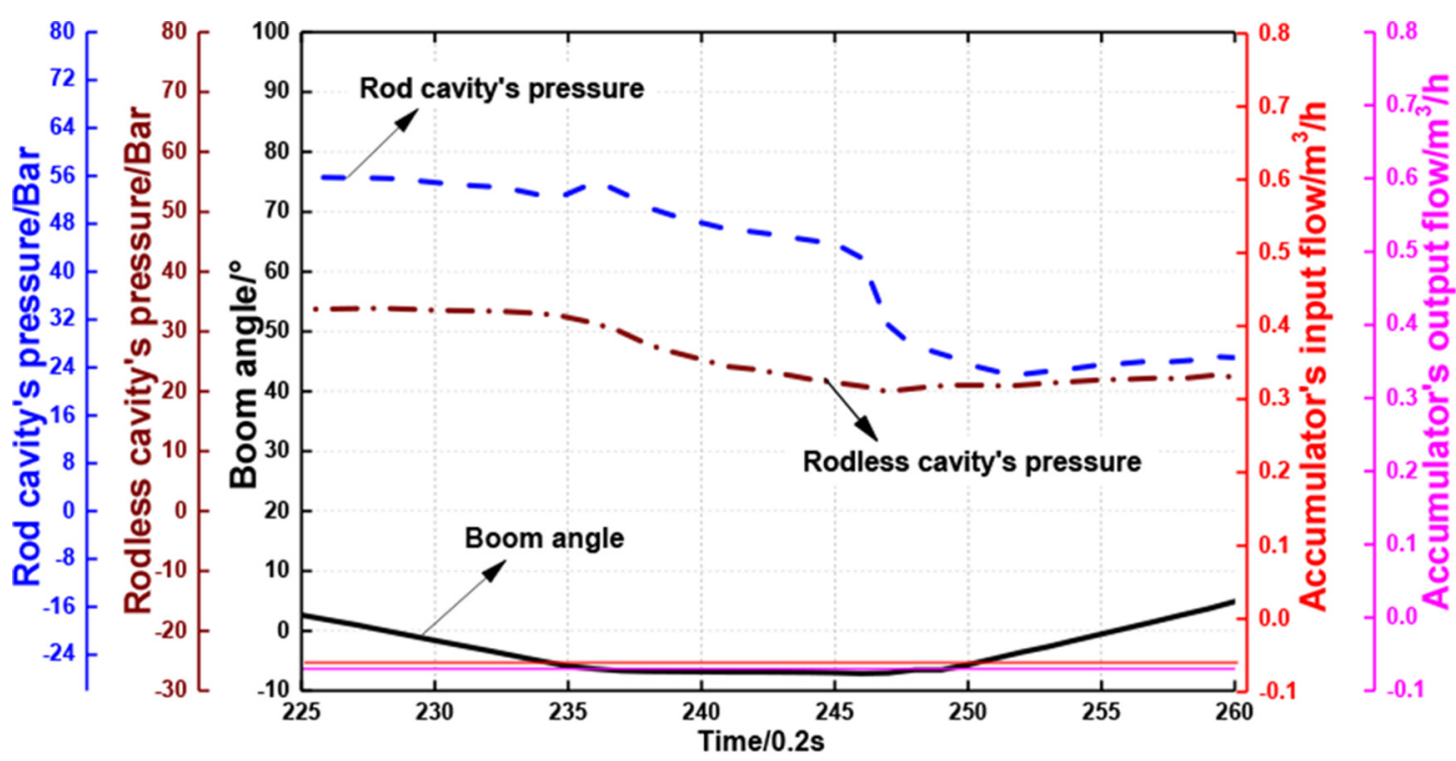

(a)

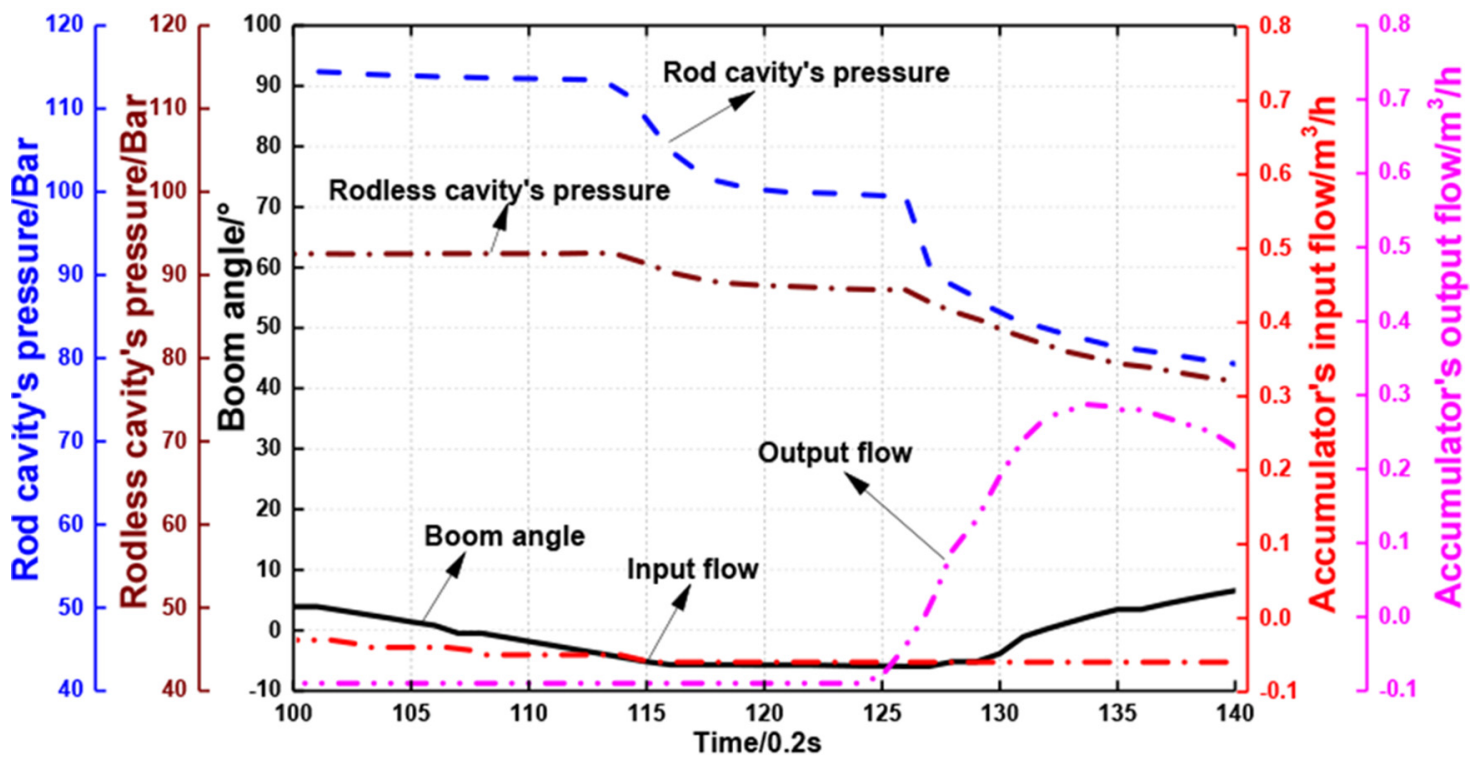

(b)

Fig. 17. Cylinder's waiting stage. (a) Corresponding without accumulator. (b) Corresponding with accumulator.

pressure fluctuation when absorbing the oil. The angle changes smoothly in the whole stage.

\section{Waiting stage}

In the waiting stage, the valve-core goes back to the zero position, and the pressure is shown in Figure 17. The pressure decreases because of the oil leakage. In particular, the pressure drop is obvious. When the accumulator is added, the pressure drops slowly and the fluctuation is small.
Conclusion: In the waiting stage, the accumulator plays a stabilizing role, and the pressure-changing range is less than in the condition without the accumulator.

\section{Outstretch stage}

The cylinder's movement is shown in Figure 18. When the accumulator is connected, the pump and accumulator supply the oil together. The cylinder outstretches rapidly at the beginning, and then tends to be smooth. The experimental process is in accordance with the simulation 


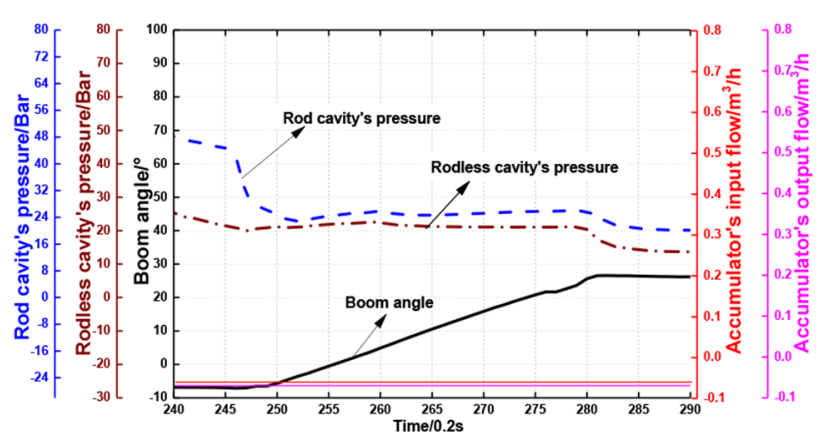

(a)

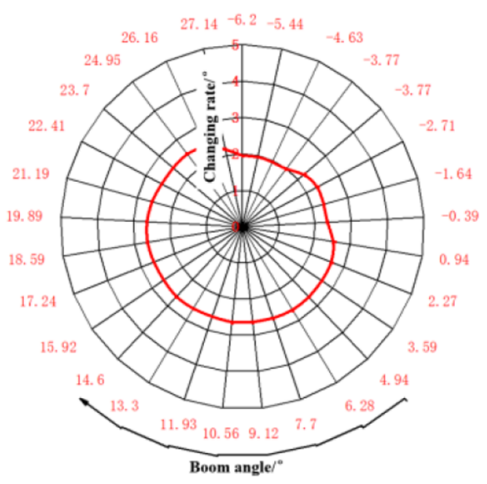

(c)

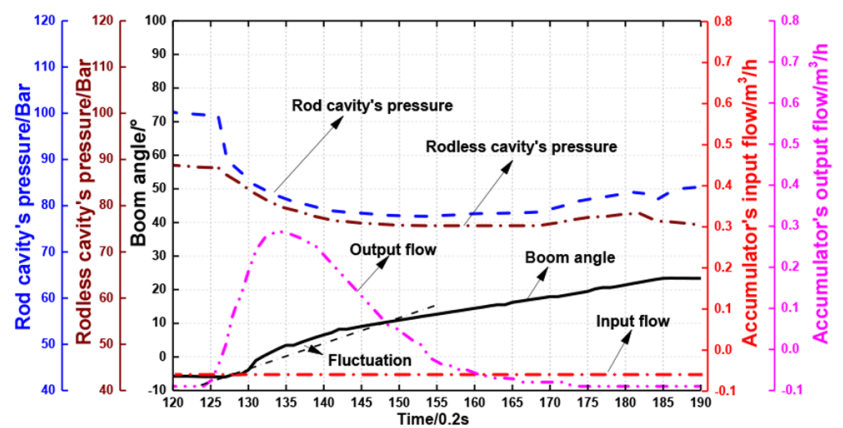

(b)

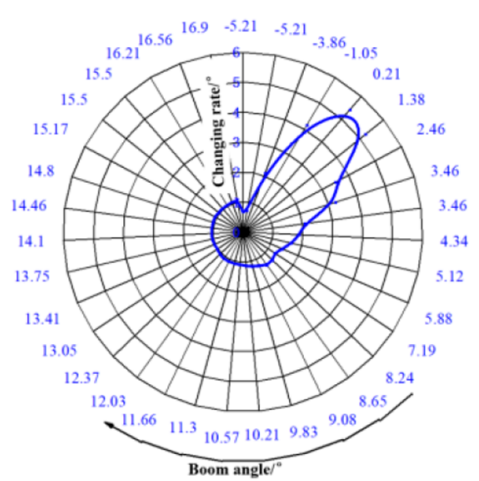

(d)

Fig. 18. Cylinder's stretched stage. (a) Corresponding without accumulator. (b) Corresponding with accumulator. (c) Angle changing rate without accumulator. (d) Angle changing rate with accumulator.

results in Figure 5. The boom angle's changing rate with the accumulator shows that the angle changes violently, and the cylinder's movement linearity is poor.

Conclusion: In the cylinder's outstretch stage, the accumulator releases energy to assist the outstretch movement, and at the same time, the velocity changes unsteadily with the phenomenon of velocity fluctuation.

\section{Waiting stage}

As shown in Figure 19, the pressure decreases obviously without the accumulator. By comparison, the pressure's change is small with the accumulator, and due to the disappearance of inertia force, the pressure increases to keep the balance state.

Conclusion: In the cylinder's waiting phase, the cylinder's pressure is more stable with the accumulator. The accumulator shows its shock-absorption function.

\subsubsection{Influence of wave compensation in several periods}

In this test, the swing platform is used to simulate the ship's movement with a frequency of $0.11 \mathrm{~Hz}$ and an amplitude of $\pm 7^{\circ}$. To keep the arm stable, the PID algorithm is used to conduct the wave compensation experiment. The simulation in Figures 9 and 10 is conducted in one cycle, and the following experiments are carried out in multiple cycles.

\section{Wave compensation without the accumulator}

The experimental curves without the accumulator are shown in Figure 20. The cylinder's pressure is unstable. The pressure's fluctuation scope rises up to $1.0 \times 10^{6} \mathrm{~Pa}$, and the rod cavity's pressure is about $3.0 \times 10^{6} \mathrm{~Pa}$. The cylinder's movement is fast, and the compensation effect is obvious and good. The wave compensation's angle error is about $\pm 0.6^{\circ}$.

Conclusion: The wave compensation without the accumulator has good stability and easy control characters, but it has high pressure fluctuation.

\section{Wave compensation experiment with the accumulator}

The experimental curves with the accumulator are shown in Figure 21. The pressure fluctuation is small, but the dynamic compensation effect is poor, and the angle error is about $\pm 3^{\circ}$. By analyzing the control signal, it is found that the signal switches between positive and negative frequently, and the phenomenon leads to the poor performance of wave compensation. The conclusion is that the accumulator is likely to cause the cylinder to overshoot. Figure 22 shows the accumulator's oil flow, which is irregular. 


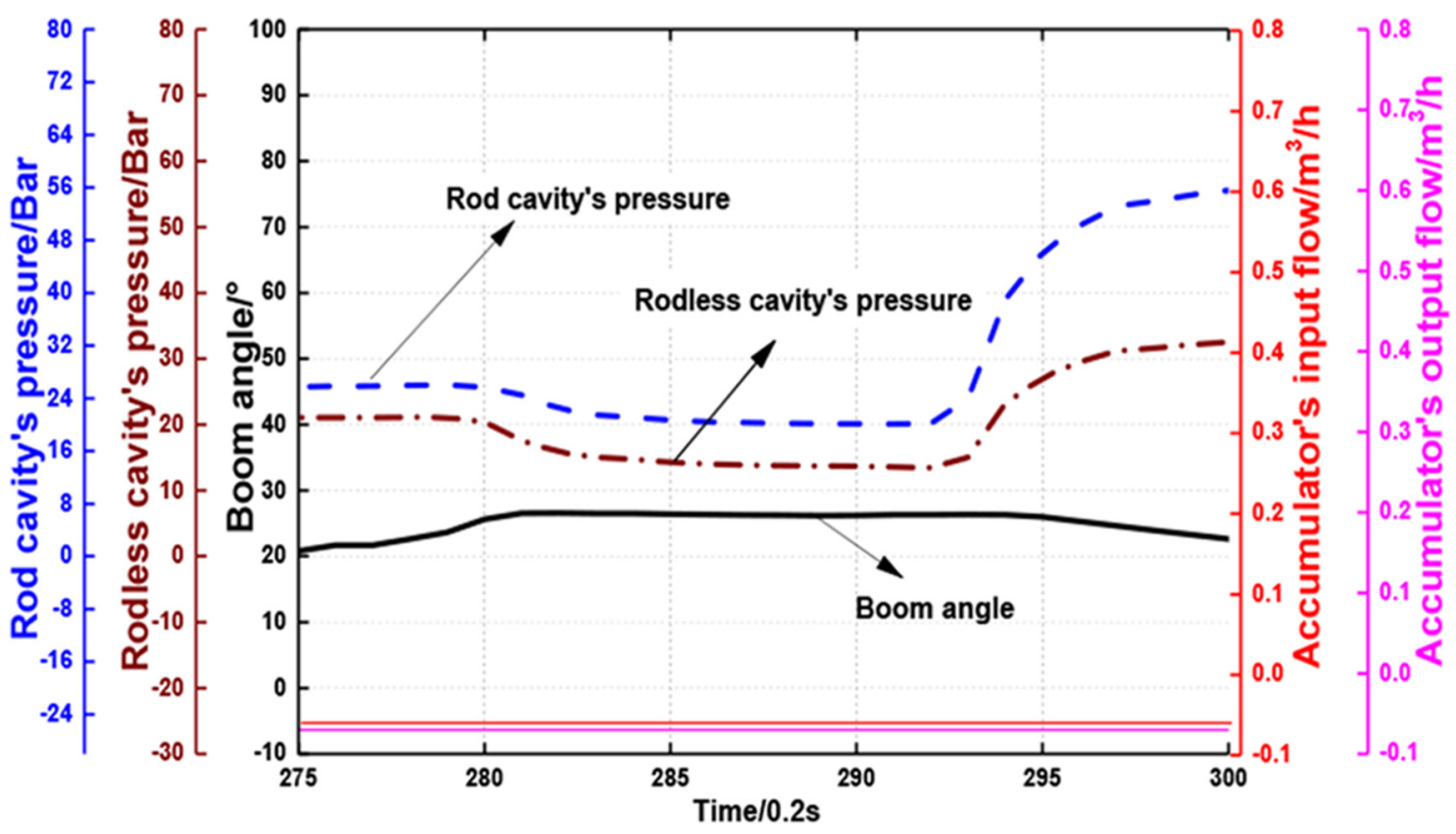

(a)

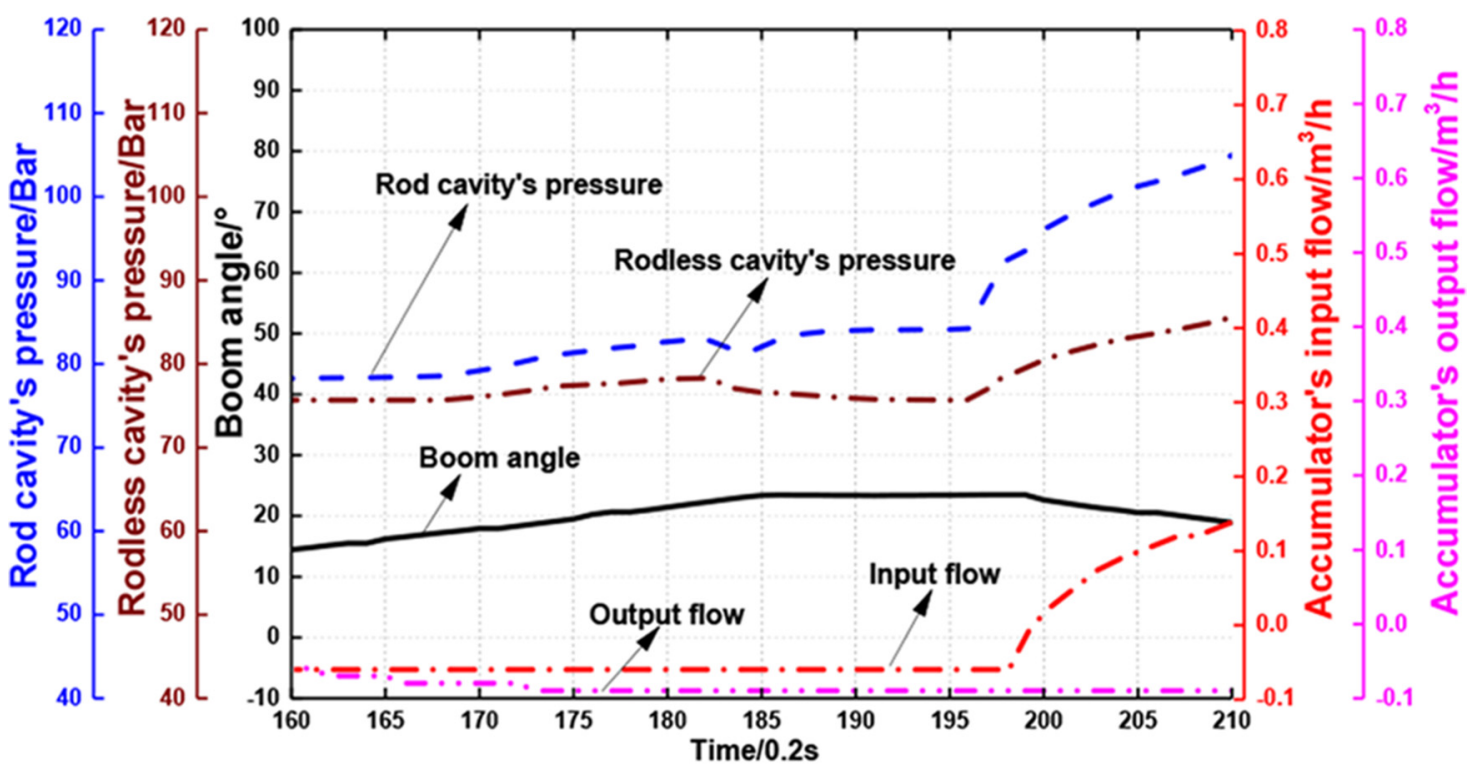

(b)

Fig. 19. Cylinder's waiting stage. (a) Corresponding without accumulator. (b) Corresponding with accumulator.

3. Solution scheme to improve wave compensation with the accumulator

The optimized method of reducing the control signal is adopted to limit the valve's oil supply, which makes the system's total power decrease according to the output flow from the accumulator. The optimized algorithm makes the cylinder extend smoothly, reduces the cylinder's jitter, and improves the effect of the wave compensation. The angle compensation deviation is stable in the range of $\pm 1^{\circ}$, as shown in Figure 23 . Figure 24 shows that the accumulator's largest output flow happens exactly at the highest angle-changing rate. The accumulator plays the role of oil supplementation source in a timely manner.

Conclusion: At the outstretch stage with the accumulator, the two oil sources cause the oil cylinder to outstretch rapidly, which is likely to lead to overshoot. The nonlinear oil supply of the accumulator 


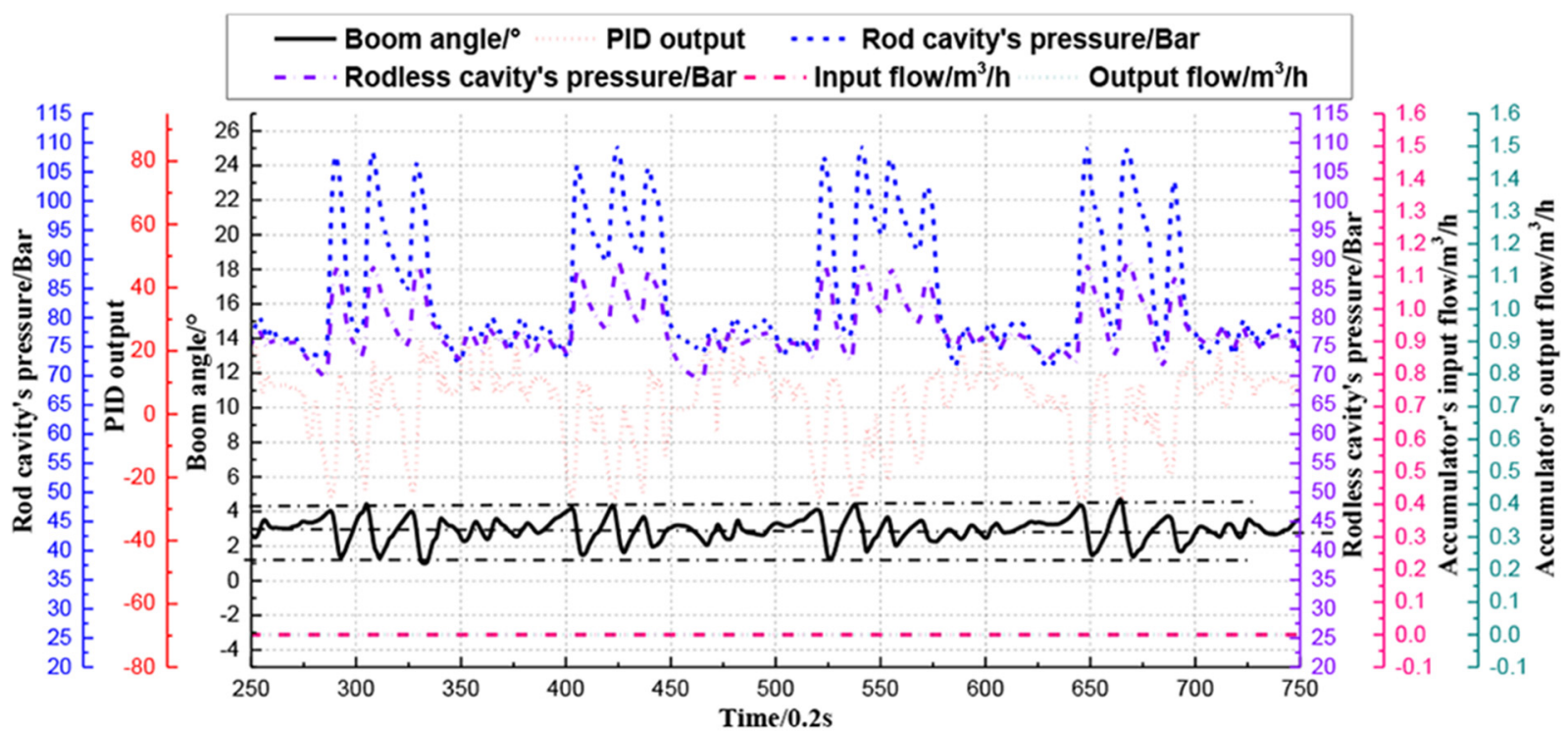

Fig. 20. Automatic wave compensation without accumulator.

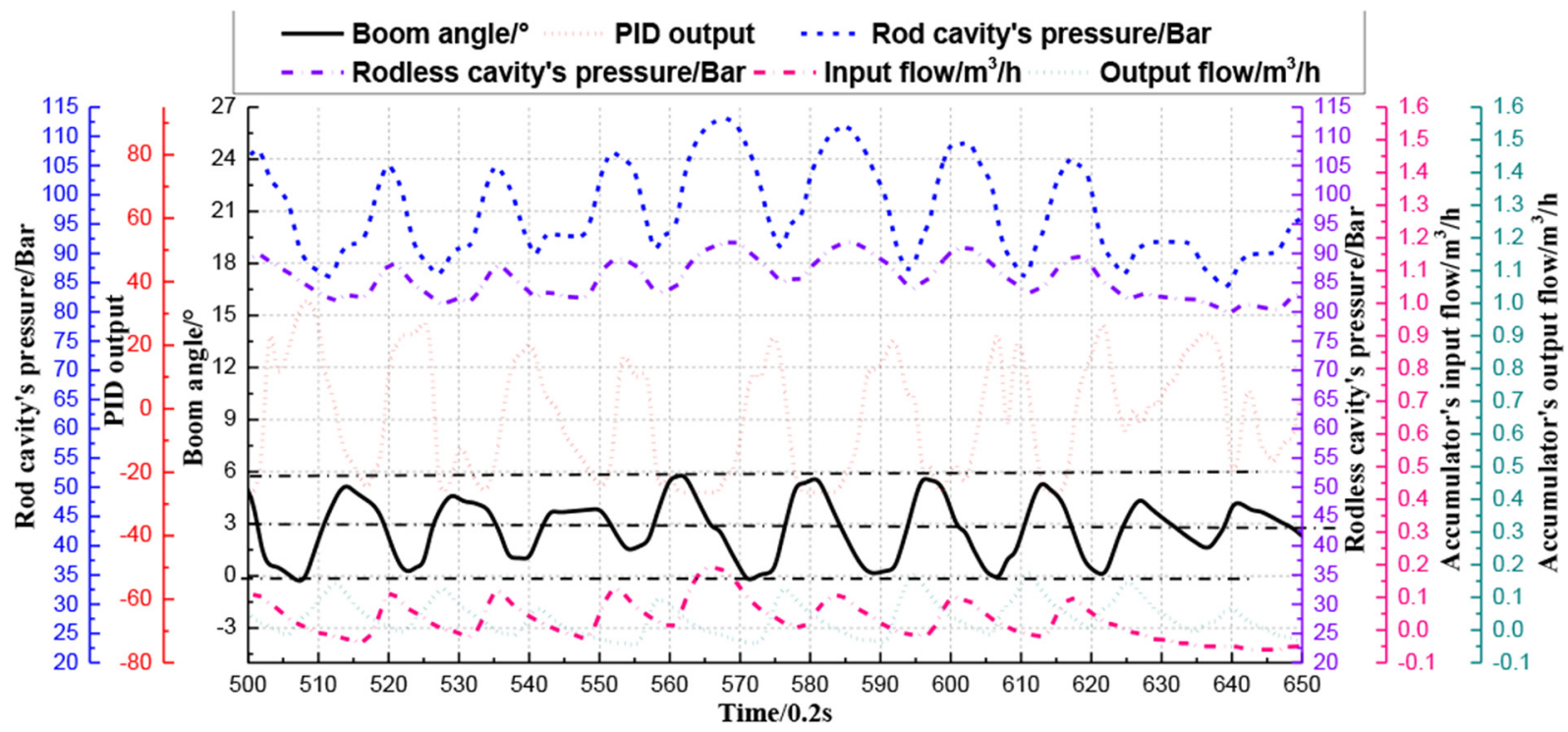

Fig. 21. Automatic wave compensation with accumulator.

causes the fluctuation of the cylinder, which results in the velocity inconsistency. To smooth the movement, the opening of the valve core should be smaller according to the accumulator's released energy, and then it can solve the fluctuation effectively.

\section{Conclusion}

The comparative analysis method is used to study the working characteristics of the accumulator, and the electro-hydraulic control law with accumulator under passive intervention is obtained.
The working pressure range of the accumulator is related to factors such as inflation pressure, accumulator volume, pipe diameter, and piston rod position. The accumulator inflation pressure $\left(6.0 \times 10^{6} \mathrm{~Pa}\right)$ should be at or slightly above $80 \%$ of the system operating minimum pressure $\left(7.56 \times 10^{6} \mathrm{~Pa}\right)$. The opening pressure of the sequence valve should be higher than the maximum working pressure $\left(9.28 \times 10^{6} \mathrm{~Pa}\right)$. The oil-absorbed velocity is significantly related to the cylinder retraction velocity and has no obvious relationship with pressure. The energyreleased velocity of the accumulator is significantly related to both the cylinder's pressure and the cylinder extension velocity. 


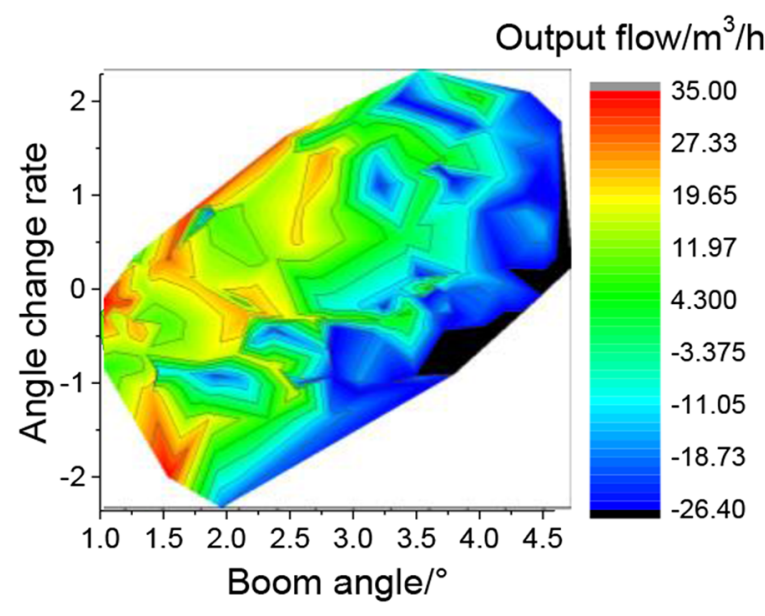

Fig. 22. Color chart of the accumulator's output flow.

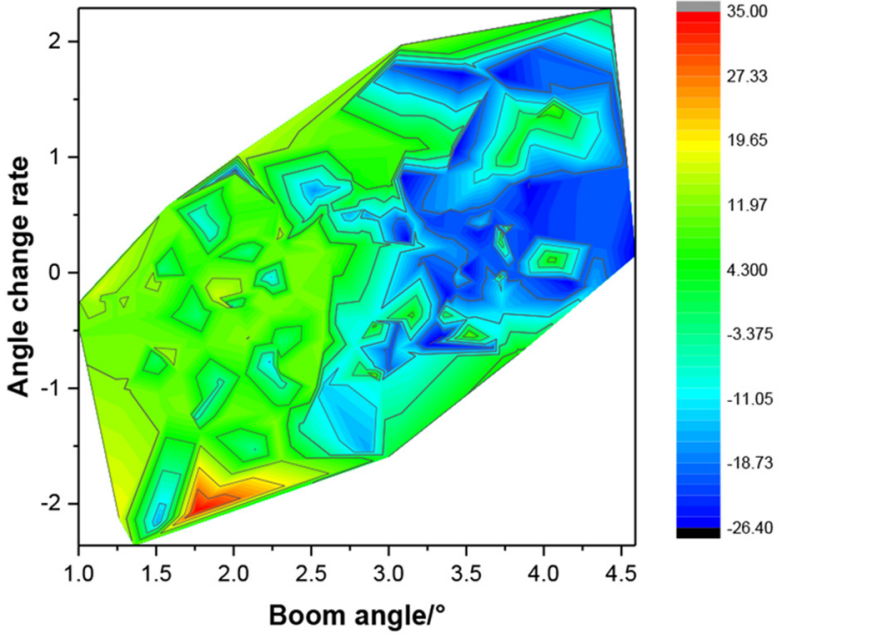

Fig. 24. Color chart of the accumulator's output flow in optimized algorithm.

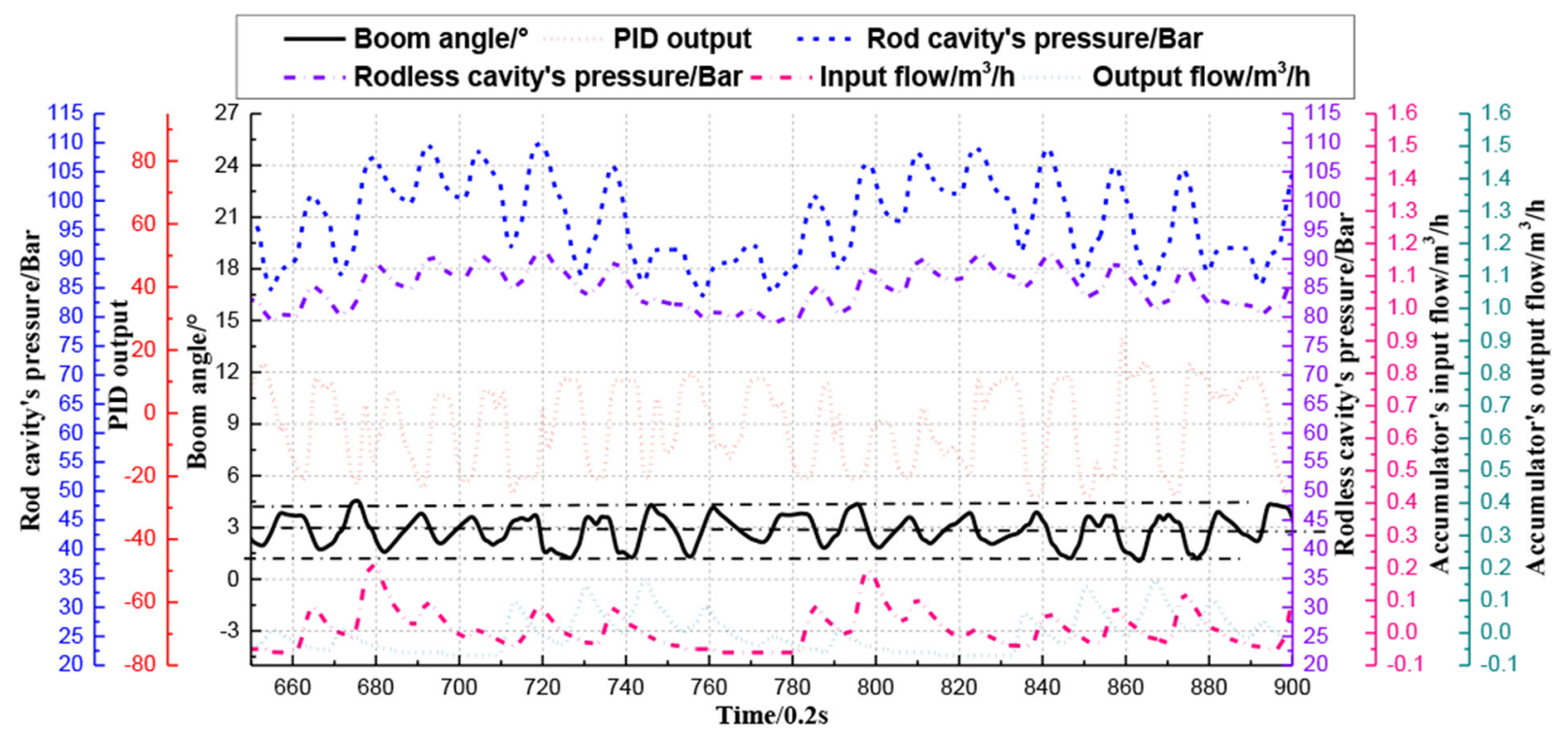

Fig. 23. Automatic wave compensation in optimized algorithm.

During the entire step response process, the accumulator stabilizes the system, and the pressure's drop scope is less. In the cylinder retraction stage, the pressure curve changes from step response to stable state. When the cylinder is extended, the accumulator releases energy to accelerate the cylinder, and the velocity becomes unstable and the volatility is large.

In electro-hydraulic control of wave compensation, the accumulator reduces the compensation effect. At the outstretch stage, the oil cylinder responds rapidly but is likely to cause overshoot. The opening of the reversing valve should be correspondingly reduced according to the potential energy characteristic curve of the accumulator to effectively solve the problem of pressure fluctuation. From another point of view, the accumulator exerts an energy-saving function in the system and reduces the energy consumption.

\section{References}

[1] M. Xu, G.J. Chen, J. Ni, Y.H. Liu, Modeling and analysis of a semiactive power-assisted unit based on hydraulic accumulator, Adv. Mech. Eng. 5 (2013) 894576

[2] X.D. Kong, L.X. Quan, The history, current situation of accumulator's research and its vista, Mach. Tool Hydraul. 10 (2004) 4-6,19 
[3] Q.L. Zhang, W. Wu, J.B. Hu, S.H. Yuan, Research on the energy storage characteristics of diaphragm accumulator, Proceedings of 2015 International Conference on Fluid Power and Mechatronics (FPM 2015), 2015, pp. 901-905

[4] J.L. Chang, L. Liu, J.Y. Zhao, H.G. Ding, G.L. Shi, The design of impact test-bed for high-flow water medium relief valve, Adv. Mech. Eng. (2014) https://doi.org/10.1155/ 2014/976896

[5] Y.K. Qiu, B.R. Li, X.Y. Fu, G. Yang J.H. Hu, Suppressing water hammer of ship steering systems with hydraulic accumulator, Proc. Inst. Mech. Eng. E J. Process Mech. Eng. 228 (2014) 136-148

[6] H. Zhang, X.X. Guo, L. Xu, S.B. Hu, Z.G. Fang, Parameters analysis of hydraulic-electrical energy regenerative absorber on suspension performance, Adv. Mech. Eng. (2014). https://doi.org/10.1155/2014/836502

[7] J.W. Zhang, S.Z. Chen, Modelling and study of active vibration control for off-road vehicle. Veh. Syst. Dyn. 52 (2014) 581-607

[8] W. Bingbing, S. Guanglin, Y. Licheng, Modeling and analysis of the electro-hydraulic proportional valve controlled motor system supplied by variable pressure accumulator, Proceedings of the 2015 International Conference on Fluid Power and Mechatronics, 2015, pp. $1165-1170$

[9] F. Ding, X. Han, N. Zhang, Z. Luo, Characteristic analysis of pitch-resistant hydraulically interconnected suspensions for two-axle vehicles, J. Vib. Control 21 (2015) 3167-3188

[10] D. Han, L. Xin-Hui et al., Impact of main parameters of accumulator on parallel hydraulic hybrid, J. Jilin Univ. 45 (2015) 420-428

[11] F.A. Ansari, R. Ranjan, D.N. Korade, K.R. Jagtap, Characterization of hydraulic suspension system, on the basis of accumulator pressure values for a special purpose vehicle, Mater Today Proc. 4 (2017) 709-716

[12] J. Zhao, N. Zhang, J.C. Ji, Steady-state response of fluidstructure interactions in hydraulic piping system of passive interconnected suspensions, Int. J. Veh. Des. 72 (2016) 305-331

[13] L. Lu, B. Yao, Energy-saving adaptive robust control of a hydraulic manipulator using five cartridge valves with an accumulator, IEEE Trans. Ind. Electron. 61 (2014) 70467054

[14] T. Minav, H. Hanninen, A. Sinkkonen, L. Laurila, J. Pyrhonen, Electric or hydraulic energy recovery systems in a reach truck: a comparison, Stroj Vestn J. Mech. Eng. 60 (2014) 232-240

[15] S.Y. Lee, B.N.M. Truong, K.K. Ahn, 15th International Conference on Control, Automation and Systems, IEEE, Busan, South Korea, 2015, pp. 1941-1945

[16] M. Xu, J. Ni, G.J. Chen, Dynamic simulation of variablespeed valve-controlled-motor drive system with a powerassisted device, Stroj Vestn J. Mech. E 60 (2014) 581-591

[17] H. Kogler, R. Scheidl, Linear motion control with a lowpower hydraulic switching converter - Part I: concept, test rig, simulations, Proc. Inst. Mech. Eng. I J. Syst. Control Eng. 229 (2015) 677-684
[18] C.H. Liu, Q.J. Yang, W. Feng, G. Bao, Maximum wave power absorption by a control strategy through combining hydraulic cylinders, Proceedings of the 2015 International Conference on Fluid Power and Mechatronics, 2015, pp. 337-343

[19] M. Liermann, O. Samhoury, S. Atshan, Energy efficiency of pneumatic power take-off for wave energy converter, Int. J. Marine Energy 13 (2016) 62-79

[20] W. Shen, J. Jiang, X. Su, H. Reza Karimi, Control strategy analysis of the hydraulic hybrid excavator, J. Franklin Inst. 352 (2015) 541-561

[21] P.Y. Zhao, Y.L. Chen, H. Zhou, Simulation analysis of potential energy recovery system of hydraulic hybrid excavator, Int. J. Precis. Eng. Manage. 18 (2017) 15751589

[22] L.P. Xia, L. Quan, L. Ge, Y.X. Hao, Energy efficiency analysis of integrated drive and energy recuperation system for hydraulic excavator boom, Energy Convers. Manage. 156 (2018) 680-687

[23] Y. Xiao, C. Guan, X. Lai, Research on the design and control strategy for a flow-coupling-based hydraulic hybrid excavator, Proc. Inst. Mech. Eng. D J. Autom. Eng. 228 (2014) $1675-1687$

[24] S.Y. Yang, Y.B. Ou, Y. Guo, XM Wu, Analysis and optimization of the working parameters of the impact mechanism of hydraulic rock drill based on a numerical simulation, Int. J. Precis. Eng. Manage. 18 (2017) 971-977

[25] H. Junke, C. Zhen, Research on lifting cylinder's pressure stability control method of active scraper, Int. Conf. Mech. Syst. Control Eng. (2017) 250-254

[26] Q. Zhang, J.H. Fang, J.H. Wei, Y. Xiong, G. Wang, Adaptive robust motion control of a fast forging hydraulic press considering the nonlinear uncertain accumulator model, Proc. Inst. Mech. Eng. I J. Syst. Control Eng. 230 (2016) 483-497

[27] G.Y. Chen, Y. Zhang, L. Ji, R. Hou, J.G. Chang, Study on new control system of electro-hydraulic proportional valve-control fast forging press, IEEE 11th Conference on Industrial Electronics and Applications, 2016, pp. 251-255

[28] T. Minav, M. Pietola, D.M. Filatov, A.V. Devyatkin, J. Heikkinen, Fuzzy control of direct-driven hydraulic drive without conventional oil tank, XX IEEE International Conference on Soft Computing and Measurements, 2017, pp. $444-447$

[29] T.L. Lin, Q. Chen, H.L. Ren, Y. Zhao, C. Miao, S.J. Fu et al., Energy regeneration hydraulic system via a relief valve with energy regeneration unit, Appl. Sci. 7 (2017) 613

[30] J. Siebert, M. Wydra, M. Geimer, Efficiency improved load sensing system reduction of system inherent pressure losses, Energies 10 (2017) 941

[31] H. Kogler, R. Scheidl, Energy efficient linear drive axis using a hydraulic switching converter, J. Dyn. Syst. Meas. Control 138 (2016) 091010

[32] F. Yoshida, S. Iio, K. Ito, A. Kitagawa, Experimental and theoretical analysis of active charge accumulator for water hydraulics system, IEEE Access 5 (2017) 881-890 
[33] J. Valdovinos, G.P. Carman, Development of a low-voltage piezohydraulic pump for compact hydraulic systems, Smart Mater. Struct. 24 (2015) 125008

[34] J.D. Van de Ven, Constant pressure hydraulic energy storage through a variable area piston hydraulic accumulator, Appl. Energy 105 (2013) 262-270
[35] H.E. Merritt, Hydraulic control systems John Wiley BT \& Sons, Inc. New York, 1967

[36] X.D. Kong, L.X. Quan, J. Yao, C. Kan, S.Q. Kang, X.C. Song, Accumulator is modeled on its stressing model and experiments research, Chin. Hydraul. Pneum. 7 (2006) 31-34

Cite this article as: Z.Q. Xu, W.L. Li, X.Y. Liu, Z.X. Chen, Dynamic characteristics of coupling model of valve-controlled cylinder parallel accumulator, Mechanics \& Industry 20, 306 (2019) 